\title{
Detailed Analysis of Apoptosis and Delayed Luminescence of Human Leukemia Jurkat T Cells after Proton Irradiation and Treatments with Oxidant Agents and Flavonoids
}

\author{
Irina Baran, ${ }^{1}$ Constanta Ganea, ${ }^{1}$ Simona Privitera, ${ }^{2,3}$ Agata Scordino, ${ }^{2,3}$ \\ Vincenza Barresi, ${ }^{4}$ Francesco Musumeci, ${ }^{2,3}$ Maria Magdalena Mocanu, ${ }^{1}$ \\ Daniele F. Condorelli, ${ }^{4}$ Ioan Ursu, ${ }^{5}$ Rosaria Grasso, ${ }^{2,3}$ Marisa Gulino, ${ }^{6}$ \\ Alexandru Garaiman, ${ }^{1}$ Nicolò Musso, ${ }^{4}$ Giuseppe A. Pablo Cirrone, ${ }^{2}$ and Giacomo Cuttone ${ }^{2}$ \\ ${ }^{1}$ Department of Biophysics, "Carol Davila" University of Medicine and Pharmacy, 8 Eroii Sanitari, 050474 Bucharest, Romania \\ ${ }^{2}$ Istituto Nazionale di Fisica Nucleare, Laboratori Nazionali del Sud, via S. Sofia, 95125 Catania, Italy \\ ${ }^{3}$ Dipartimento di Fisica e Astronomia, Università di Catania, Viale A. Doria 6, 95125 Catania, Italy \\ ${ }^{4}$ Sezione di Biochimica e Biologia Molecolare, Dipartimento di Scienze Chimiche, Università di Catania, 6 A. Doria, \\ 95125 Catania, Italy \\ 5 "Horia Hulubei" National Institute for Physics and Nuclear Engineering (IFIN-HH), 30 Reactorului, 077125 Bucharest, Romania \\ ${ }^{6}$ Università degli Studi di Enna "Kore", Facoltà di Ingegneria, Architettura e delle Scienze Motorie, Cittadella Universitaria, \\ 94100 Enna, Italy
}

Correspondence should be addressed to Irina Baran, baran@ifin.nipne.ro

Received 9 March 2012; Accepted 14 May 2012

Academic Editor: Cristina Angeloni

Copyright ( 2012 Irina Baran et al. This is an open access article distributed under the Creative Commons Attribution License, which permits unrestricted use, distribution, and reproduction in any medium, provided the original work is properly cited.

\begin{abstract}
Following previous work, we investigated in more detail the relationship between apoptosis and delayed luminescence (DL) in human leukemia Jurkat T cells under a wide variety of treatments. We used menadione and hydrogen peroxide to induce oxidative stress and two flavonoids, quercetin, and epigallocatechin gallate, applied alone or in combination with menadione or $\mathrm{H}_{2} \mathrm{O}_{2} .62$ $\mathrm{MeV}$ proton beams were used to irradiate cells under a uniform dose of 2 or $10 \mathrm{~Gy}$, respectively. We assessed apoptosis, cell cycle distributions, and DL. Menadione, $\mathrm{H}_{2} \mathrm{O}_{2}$ and quercetin were potent inducers of apoptosis and DL inhibitors. Quercetin decreased clonogenic survival and the $\mathrm{NAD}(\mathrm{P}) \mathrm{H}$ level in a dose-dependent manner. Proton irradiation with $2 \mathrm{~Gy}$ but not $10 \mathrm{~Gy}$ increased the apoptotic rate. However, both doses induced a substantial $\mathrm{G}_{2} / \mathrm{M}$ arrest. Quercetin reduced apoptosis and prolonged the $\mathrm{G}_{2} / \mathrm{M}$ arrest induced by radiation. DL spectroscopy indicated that proton irradiation disrupted the electron flow within Complex I of the mitochondrial respiratory chain, thus explaining the massive necrosis induced by $10 \mathrm{~Gy}$ of protons and also suggested an equivalent action of menadione and quercetin at the level of the Fe/S center N2, which may be mediated by their binding to a common site within Complex I, probably the rotenone-binding site.
\end{abstract}

\section{Introduction}

During the past decades there has been a steadily growing interest in the benefits of natural flavonoids. These compounds which are ubiquitously occurring in fruits, vegetables, and tea possess chemopreventive, cardioprotective, anticancer, anti-inflammatory, antiallergenic, and anti-microbial properties. Epigallocatechine-3-gallate (EGCG) and quercetin (QC; 3,5,7,3',4'-pentahydroxyflavone) are two wellinvestigated flavonoids which inhibit cell proliferation and induce apoptosis in various cancer cell types [1-9]. Both
EGCG and QC can exert a dual, pro- and antioxidant effect, depending on dosage and time of treatment, and numerous studies have indicated that malignant cells are more susceptible than normal cells to the cytotoxicity of these two flavonoids [2, 7-9]. At present, only a few agents are known to possess such potential for selective/preferential elimination of cancer cells while exerting cytoprotective effects on normal cells [2]. Therefore, this property could be exploited to prevent leukemia or to increase the efficiency of leukemia chemotherapies. 
At the moment, the antiproliferative effects of EGCG and QC and their dose dependence in human acute lymphoblastoid leukemia Jurkat T cells are largely unknown. It has been shown that QC can accumulate in large quantities inside the mitochondria, where it is stored in a biologically active form bound to mitochondrial proteins [10]. QC can also act as an activator or inhibitor of the mitochondrial permeability transition pore, depending on its pro- or antioxidant character, respectively [11]. QC is able to inhibit Complexes I and III of the mitochondrial electron transport chain (ETC) [12] and participate in quinone redox cycling [8, 13]. At high doses, QC enhances the cellular production of hydrogen peroxide $\left(\mathrm{H}_{2} \mathrm{O}_{2}\right)$ and superoxide $\left(\mathrm{O}_{2}{ }^{-\bullet}\right)[9,11,14] . \mathrm{O}_{2}^{-\bullet}$ can be then dismutated to $\mathrm{H}_{2} \mathrm{O}_{2}$ by cytosolic or mitochondrial superoxide dismutases. Furthermore, additional $\mathrm{OH}^{\bullet}$ can be produced from $\mathrm{H}_{2} \mathrm{O}_{2}$ through $\mathrm{Fe} / \mathrm{Cu}$-dependent Fenton reactions. At low doses $(\sim 10 \mu \mathrm{M})$ QC exercises protective effects against $\mathrm{H}_{2} \mathrm{O}_{2}$ but not $\mathrm{MD}$ in Jurkat cells [15]. When applied for short periods, quercetin can decrease the cellular $\mathrm{H}_{2} \mathrm{O}_{2}$ content, whereas in long-term administration it depresses the level of the endogenous antioxidant GSH (reduced glutathione). This in turn may lead to accelerated production of reactive oxygen species (ROS) and toxic metabolites of quercetin $[9,11,14,16,17]$. Recent studies have shown that in Jurkat cells low EGCG concentrations $(\sim 10 \mu \mathrm{M})$ exhibit a protective, antioxidant effect, whereas high concentrations $(\sim 100 \mu \mathrm{M})$ have a prooxidant, cyto, and genotoxic effect, inducing DNA lesions even in the absence of exogenous oxidant agents [1]. In Jurkat cells, EGCG $(50 \mu \mathrm{M})$ produces intracellular $\mathrm{H}_{2} \mathrm{O}_{2}$, which induces apoptosis by a $\mathrm{Fe}^{2+}$-dependent mechanism, through generation of hydroxyl radicals via Fenton reactions [5]. In a different cell type, EGCG has been shown to associate with mitochondria and other yet unidentified cytoplasmic organelles [18].

A clinically important chemotherapeutic agent used in the treatment of leukemia is menadione (vitamin $K_{3}$ ) $[6,19]$. Early studies have revealed that menadione (MD) reduction at Complex I of the mitochondrial ETC $[20,21]$ accounts for $\sim 50 \%$ of MD metabolism [21]. As a consequence, MD can increase superoxide production by disrupting the electron flow within Complex I [21]. $\mathrm{MD}, \mathrm{H}_{2} \mathrm{O}_{2}$, EGCG, and QC can activate the apoptotic program in various cell types via a $\mathrm{Ca}^{2+}$-dependent mitochondrial pathway, which is mediated by elevation of cytosolic $\mathrm{Ca}^{2+}$ levels and dissipation of the mitochondrial membrane potential $[7,11,12,19,22-26]$. However, the current available data on the effects of these compounds on the cell cycle or apoptosis/necrosis in Jurkat cells are extremely limited.

In this work we have extended our previous studies [15] and carried out a thorough investigation of the relationship between apoptosis and delayed luminescence (DL) under a vast range of conditions induced by oxidative stress, flavonoid treatments, and irradiation with $62 \mathrm{MeV}$ proton beams (some preliminary data were reported in [27]). We have performed a detailed analysis of the kinetics of apoptosis induction and cell cycle progression following various treatments. Moreover, we have investigated for the first time the effects of high-energy protons on these cells and found that this type of radiation preferentially induces necrosis, not apoptosis in Jurkat cells, as well as arrest of the cell cycle in the $\mathrm{G}_{2} / \mathrm{M}$ phase. This may have relevant implications in radiotherapy, as it is generally known that the radiosensitivity of human leukemia Jurkat $\mathrm{T}$ cells is relatively high [25, 28-30]. In addition, it has been reported that high doses $(\geq 10 \mathrm{~Gy})$ of $\mathrm{X}$ or $\gamma$ radiation induce significant apoptosis in Jurkat cells, in a time- and dose-dependent manner $[25,29,30]$. Thus, our investigations suggest a differential effect on cell death induction depending on the type of radiation. Moreover, quercetin was able to reduce apoptosis and prolong the $\mathrm{G}_{2} / \mathrm{M}$ arrest induced by proton irradiation.

In addition, our current data obtained by DL spectroscopy provide novel insights into the effects of $\mathrm{MD}, \mathrm{H}_{2} \mathrm{O}_{2}$, EGCG, QC, and high-energy protons at the level of mitochondrial Complex I. Delayed luminescence, which is also called "delayed fluorescence", represents a very weak light emission following exposure to pulsed light or UV radiation [31-43]. Its main characteristics are the multicomponent decay pattern of photoemission and the long-time scale of the process. In this work, DL spectroscopy indicated that proton irradiation disrupted the electron flow within Complex I of the mitochondrial respiratory chain and also suggested an equivalent action of menadione and quercetin at the level of Complex I.

\section{Materials and Methods}

The experiments and methodologies described in this study were generally conducted as described earlier $[15,27,44]$.

2.1. Cell Cultures. Human leukemia Jurkat T-cell lymphoblasts were cultured in suspension in MegaCell RPMI 1640 medium supplemented with 5\% heat-inactivated fetal bovine serum, $2 \mathrm{mM}$ L-glutamine, 100 units/mL penicillin, and $100 \mu \mathrm{g} / \mathrm{mL}$ streptomycin, at $37^{\circ} \mathrm{C}$ in a humidified incubator with a $5 \% \mathrm{CO}_{2}$ atmosphere. Exponentially growing cells were adjusted to a density of $0.2 \times 10^{6}$ cells $/ \mathrm{mL}$ the day before the experiment. We used hydrogen peroxide $30 \%$ solution and stock solutions of menadione sodium bisulphite dissolved in phosphate buffer saline (PBS) or dehydrated quercetin and epigallocatechin gallate dissolved in dimethyl sulfoxide (DMSO). In combined treatments, the oxidant agent was added directly to the cell cultures after preincubation with QC or EGCG as specified, without intermediary wash out. Unless specified otherwise, all chemicals were from Sigma-Aldrich. After each treatment, cells were washed thoroughly with PBS and resuspended in PBS (for DL samples, $\sim 40 \times 10^{6}$ cells $/ \mathrm{mL}$ ) or in complete medium for apoptosis assessment $\left(\sim 0.2 \times 10^{6}\right.$ cells $\left./ \mathrm{mL}\right)$. DL samples were analyzed immediately by DL spectroscopy. Cell density, viability, and morphology were examined with a CCD camera Logitech QuickCam Pro 4000, connected to an Olympus CK30 phase contrast microscope. For cell density assessment, $25 \mu \mathrm{L}$ aliquots of the DL samples was diluted in PBS, stained with $0.4 \%$ trypan blue solution and $\sim 1500-2000$ cells were imaged on a Bürker haemocytometer at the time of the DL assay. Cell count evaluation was performed both during DL experiments, directly by visual inspection under the 
microscope, and later on, by analyzing the micrographs with the use of the software ImageJ.

2.2. Proton Irradiation. Cell suspensions $(7 \mathrm{~mL})$ were irradiated in $50 \mathrm{~mL}$ centrifuge tubes fixed in a vertical position. $62 \mathrm{MeV}$ proton beams accelerated by the superconducting cyclotron at LNS-INFN, Catania (Italy) were used for proton irradiation at a dose rate of $11.76 \mathrm{~Gy} / \mathrm{min}$. The proton beams were modulated in the wide-spread Bragg peak configuration, to produce a uniform distribution of the absorbed dose in the entire cell suspension. A plane-parallel advanced PTW 34045 Markus ionization chamber was adopted as a reference dosimeter. The dose measurements were performed in a water phantom, according to International Atomic Energy Agency (IAEA) TRS 398. The absorbed dose to water per monitor unit (cGy/M.U.) was measured at the isocenter, at the depth corresponding to the middle of the modulated beam, with the reference circular collimator (diameter = $25 \mathrm{~mm})$.

2.3. Clonogenic Survival Assay. After the treatment, cells were washed thoroughly with warm PBS and plated in 96 well plates at a plating density of 3,4 , or 10 cells/well in $100 \mu \mathrm{L}$ of complete medium per well. After 4 weeks of incubation, the plates were inspected by microscopy and the wells containing colonies with $>50$ cells were counted. The plating efficiency was calculated as $\ln [96 /$ (no. of negative wells) $] /$ (plating density) $\times 100$. Clonogenic survival was calculated as the ratio between the plating efficiency of treated and control cells, respectively.

2.4. Flow Cytometry. At specified times after the treatment, samples containing $10^{6}$ cells were fixed in $70 \%$ ethanol and frozen at $-20^{\circ} \mathrm{C}$. For flow-cytometer determinations, the ethanol-fixed samples were washed with PBS, incubated with a propidium iodide PI/RNAse staining buffer (PHARMINGEN 550825) for $15 \mathrm{~min}$, in the dark at room temperature and analyzed with a Becton Dickinson FACS Calibur flow cytometer. For data acquisition and analysis we used the software CellQuest, WinMDI 2.9 and Cylchred, together with a Gaussian deconvolution algorithm as described [15]. Apoptosis was evaluated as the fraction of hypodiploid cell fragments (the sub- $G_{0} / G_{1}$ cell fraction). The $G_{0} / G_{1}, S$, and $\mathrm{G}_{2} / \mathrm{M}$ cell fractions were calculated for the nonapoptotic cell population, by excluding the hypodiploid events from the cell cycle analysis.

2.5. Delayed Luminescence Spectroscopy. We used an improved version of the ARETUSA set-up [39], a highly sensitive equipment able to detect single photons. The cell samples were excited by a Nitrogen Laser source (Laser Photonics LN 230C; wavelength $337 \mathrm{~nm}$, pulse-width $5 \mathrm{~ns}$, energy $100 \pm 5 \mu \mathrm{J} /$ pulse). A multialkali photomultiplier tube (Hamamatsu R-7602-1/Q) was used as a detector for photoemission signals with wavelengths in the visible range (VIS, $400-800 \mathrm{~nm}$ ), in single photon counting mode. In some determinations, two broad band (about $80 \mathrm{~nm}$ FWHM) LotOriel interferential filters, disposed in a wheel between the sample and the photomultiplier, were used to select photons with wavelength of $460 \mathrm{~nm}$ and $645 \mathrm{~nm}$, respectively. The detected signals were acquired by a Multichannel Scaler (Ortec MCS PCI) with a minimum dwell time of $200 \mathrm{~ns}$. DL measurements were done on at least 3 different drops from each cell sample (drop volume $15-25 \mu \mathrm{L}$ ) at room temperature $\left(20 \pm 1^{\circ} \mathrm{C}\right)$. PBS luminescence was subtracted from all recordings. Photoemission was recorded between $11 \mu \mathrm{s}$ and $100 \mathrm{~ms}$ after laser excitation. DL intensity $(I)$ was obtained as the number of photons recorded within a certain time interval divided to that time interval and to the number of living cells in the drop. The quantum yield was calculated in three time domains of the DL emission: 11-100 $\mu$ s (DLI), $100 \mu \mathrm{s}-1 \mathrm{~ms}$ (DL-II), and $1-10 \mathrm{~ms}$ (DL-III), as the ratio between the I-integral and the energy of the laser. This analysis could not be performed in consistent manner in the time domain 10-100 ms, as in some cases the signal-to-noise ratio was too high within this region.

2.6. Spectrofluorimetry. For determination of the relative level of intracellular nicotinamide adenine dinucleotide and nicotinamide adenine dinucleotide phosphate in their reduced form (NADH and NADPH, resp.), denoted generically as $\mathrm{NAD}(\mathrm{P}) \mathrm{H}$, exponentially growing cells were washed twice in a standard saline solution (SS) containing $140 \mathrm{mM}$ $\mathrm{NaCl}, 5 \mathrm{mM} \mathrm{KCl}, 1 \mathrm{mM} \mathrm{CaCl}_{2}, 1 \mathrm{mM} \mathrm{MgCl} 2,20 \mathrm{mM}$ HEPES, and $10 \mathrm{mM}$ glucose, $\mathrm{pH} 7.2 / \mathrm{NaOH}$, resuspended in $\mathrm{SS}$ at $\sim 10^{6}$ cells $/ \mathrm{mL}$, and transferred into a $2 \mathrm{~mL}$ quartz cuvette maintained at $37^{\circ} \mathrm{C}$ under continuous stirring in a Horiba Jobin Yvon spectrofluorimeter. Every $22 \mathrm{~s}$ the cell sample was excited at $340 \mathrm{~nm}$ and emission was collected at $450 \mathrm{~nm}$. After stabilization of the fluorescence signal, QC at the indicated dose was added directly to the cuvette, and the kinetic recording was carried on for an additional 45-60 min. The resting value of $\mathrm{NAD}(\mathrm{P}) \mathrm{H}$ fluorescence was obtained as the average intensity recorded over the final $10 \mathrm{~min}$. before the addition of QC. To express the relative variation in the cellular NAD(P)H level, NAD(P)H fluorescence was normalized to the resting value. The background fluorescence obtained in a cuvette containing equivalent amounts of SS or SS and DMSO was correspondingly subtracted from all data.

2.7. Statistics. Unless indicated otherwise, the data are presented as median \pm s.e.m. of at least three different measurements. Statistically significant differences were determined using Student's $t$-test. A level of $P<0.05$ was considered significant in all statistical tests.

\section{Results}

3.1. Effects of Proton Radiation, $M D, \mathrm{H}_{2} \mathrm{O}_{2}$, QC, and EGCG on Apoptosis and Cell Cycle. First we assessed apoptosis and cell cycle distributions of Jurkat cells undergoing various treatments. The results are collected in Figure 1.

Some of our preliminary determinations indicated that high doses (10 Gy) of accelerated protons induce necrosis, not apoptosis in Jurkat cells [27]. Consistent with this, in the present study we found that irradiation with $2 \mathrm{~Gy}$ but not 


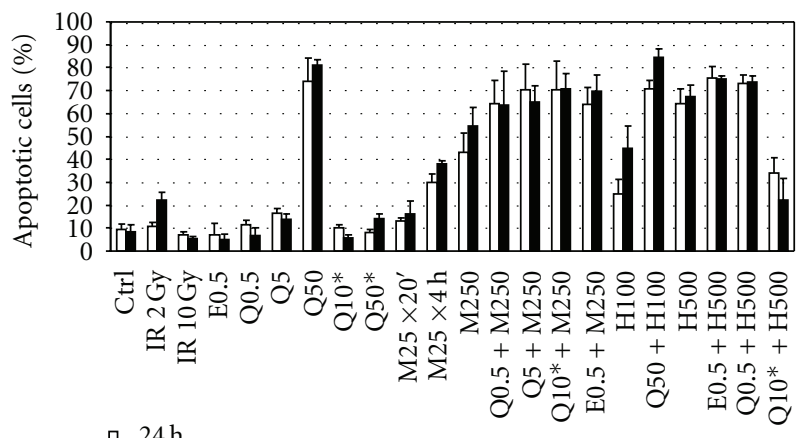

․ $24 \mathrm{~h}$

(a)

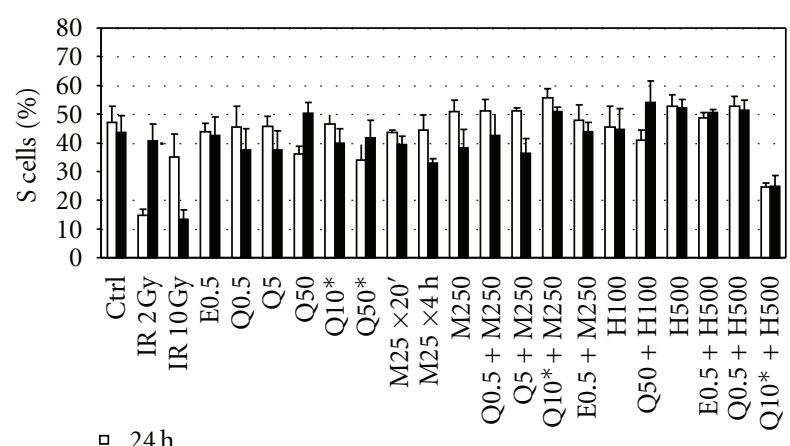

- $48 \mathrm{~h}$

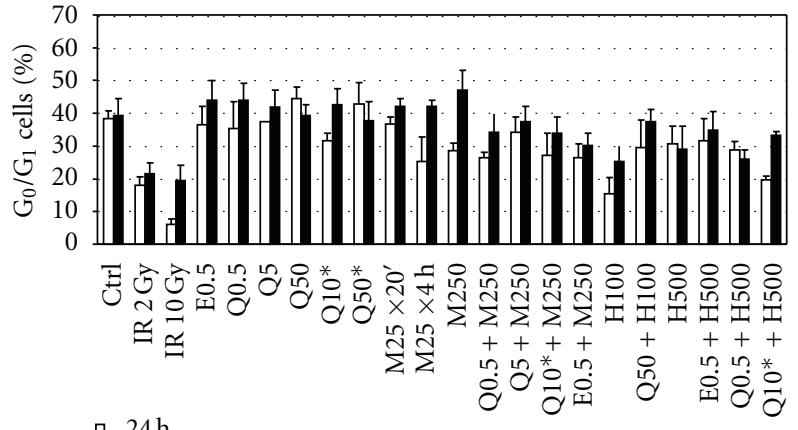

- $24 \mathrm{~h}$

- $48 \mathrm{~h}$

(b)

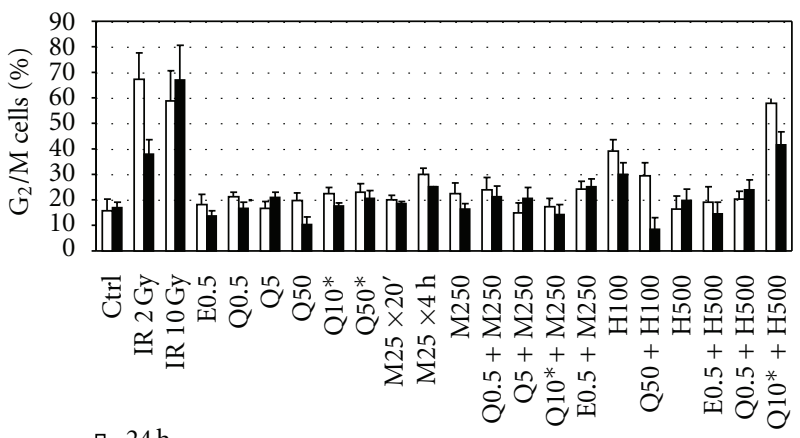

- $48 \mathrm{~h}$

(d)

FIGURE 1: Apoptosis and cell-cycle distributions assessed at 24 and $48 \mathrm{~h}$ after treatment of Jurkat cells with the vehicle (Ctrl), with $0.5,5$ or $50 \mu \mathrm{M}$ QC for $24 \mathrm{~h}(\mathrm{Q} 0.5, \mathrm{Q} 5, \mathrm{Q} 50), 10$ or $50 \mu \mathrm{M}$ QC for $1 \mathrm{~h}\left(\mathrm{Q} 10^{*}\right.$, Q50*), $0.5 \mu \mathrm{M}$ EGCG for $24 \mathrm{~h}(\mathrm{E} 0.5), 250 \mu \mathrm{M} \mathrm{MD}$ for $20 \mathrm{~min}$. (M250), 100, or $500 \mu \mathrm{M} \mathrm{H}_{2} \mathrm{O}_{2}$ for $20 \mathrm{~min}$. (H100 or H500) or after combined treatments (QC or EGCG preincubation followed by addition of $250 \mu \mathrm{M} \mathrm{MD}$ or $100 / 500 \mu \mathrm{M} \mathrm{H}_{2} \mathrm{O}_{2}$ for $20 \mathrm{~min}$.) and after irradiation with $2 \mathrm{~Gy}$ or $10 \mathrm{~Gy}$ of protons (IR $2 \mathrm{~Gy}$, IR $10 \mathrm{~Gy}$ ). Apoptotic rates (a), $\mathrm{G}_{0} / \mathrm{G}_{1}$ (b), S-phase (c), and $\mathrm{G}_{2} / \mathrm{M}$ (d) cell fractions are indicated.

10 Gy of high-energy protons produced a significant increase in the apoptotic rate at $48 \mathrm{~h}$ after irradiation (Figure 1(a), see Figure S1A,B in Supplementary Material available online at doi:10.1155/2012/498914). However, both doses consistently blocked the cell cycle at the $\mathrm{G}_{2} / \mathrm{M}$ phase within $24 \mathrm{~h}$ after irradiation, suggesting the presence of severe DNA damage in irradiated cells (Figure $1(\mathrm{~d})$ ). There was a consistent decline in the $\mathrm{G}_{2} / \mathrm{M}$ cell fraction at $48 \mathrm{~h}$ after irradiation with $2 \mathrm{~Gy}$ but not $10 \mathrm{~Gy}$ (Figure $1(\mathrm{~d})$ ), which was associated with a reduction in the S-cell pool (Figure $1(\mathrm{c})$ ), suggesting that a part of the cells receiving $2 \mathrm{~Gy}$ of protons were able to initiate apoptosis from the $\mathrm{G}_{2} / \mathrm{M}$ phase arrest whereas those receiving $10 \mathrm{~Gy}$ were too damaged to trigger apoptosis and to repair the DNA lesions. Indeed, clonogenic survival after irradiation with $10 \mathrm{~Gy}$ of protons was below the resolution of our assay (i.e., $<0.1 \%$ ), indicating that this dose of protons induced massive necrosis in this cell system, similar to other reports for $\mathrm{X}$ - or $\gamma$-irradiation $[25,29,30]$. Trypan blue exclusion tests confirmed high rates of cell death, namely, $18.4 \pm 3.2 \%$ and $46.6 \pm 6.8 \%$ at $24 \mathrm{~h}$ and $48 \mathrm{~h}$ after irradiation with $10 \mathrm{~Gy}$ of protons, respectively.

$0.5 \mu \mathrm{M}$ EGCG applied for $24 \mathrm{~h}$ did not affect the apoptotic rate or the cell cycle distribution (Figure 1) but could enhance apoptosis induced by $\mathrm{MD}$ or $\mathrm{H}_{2} \mathrm{O}_{2}$ (discussed below).
In agreement with our previous investigations [15, 27], quercetin induced apoptosis in Jurkat cells in a dose- and time-dependent manner (Figure 1(a), Figure S1C). Thus, $50 \mu \mathrm{M}$ QC delivered for $1 \mathrm{~h}$ or $24 \mathrm{~h}$ produced at $48 \mathrm{~h}$ after the treatment an apoptotic rate of $14.1 \pm 2.1 \%$ (Figure S1C) or $81.5 \pm 2.5 \%$, respectively, as compared with the corresponding rate of $8.4 \pm 3.2 \%$ in control cells (Figure S1A). From kinetic measurements it appeared that quercetin can arrest Jurkat cells in the $\mathrm{G}_{2} / \mathrm{M}$ phase (Figure 2 ). Moreover, the $\mathrm{G}_{2} / \mathrm{M}$ fraction of cells treated with $50 \mu \mathrm{M}$ QC for $24 \mathrm{~h}$ decreased from $39.8 \pm 6.4 \%$ at $9 \mathrm{~h}$ to $10.3 \pm 3.0 \%$ at $48 \mathrm{~h}$ after the treatment (Figure $2(\mathrm{~d})$ ). The $\mathrm{G}_{2} / \mathrm{M}$ block was associated with a significant reduction in the $G_{0} / G_{1}$ cell fraction (Figure 2(b)), whereas the S-phase distribution was unaltered (Figure 2(c)). The cells also displayed a consistent apoptotic rate $(52.2 \pm 7.3 \%) 9 \mathrm{~h}$ after drug removal, which then increased gradually up to $81.5 \%$ during the probing interval (Figure 2(a)). This value is in agreement with the clonogenic survival of these cells, which was determined to be $35.9 \pm 10.4 \%(n=4)$. In addition, the consistent depletion of the $\mathrm{G}_{2} / \mathrm{M}$ cell pool in the absence of significant changes in the $G_{0} / G_{1}$ and $S$-phase distributions at $48 \mathrm{~h}$ after the treatment suggests that a part of the $\mathrm{G}_{2} / \mathrm{M}$-arrested cells most likely initiated apoptosis after 1 day from the removal of quercetin. 


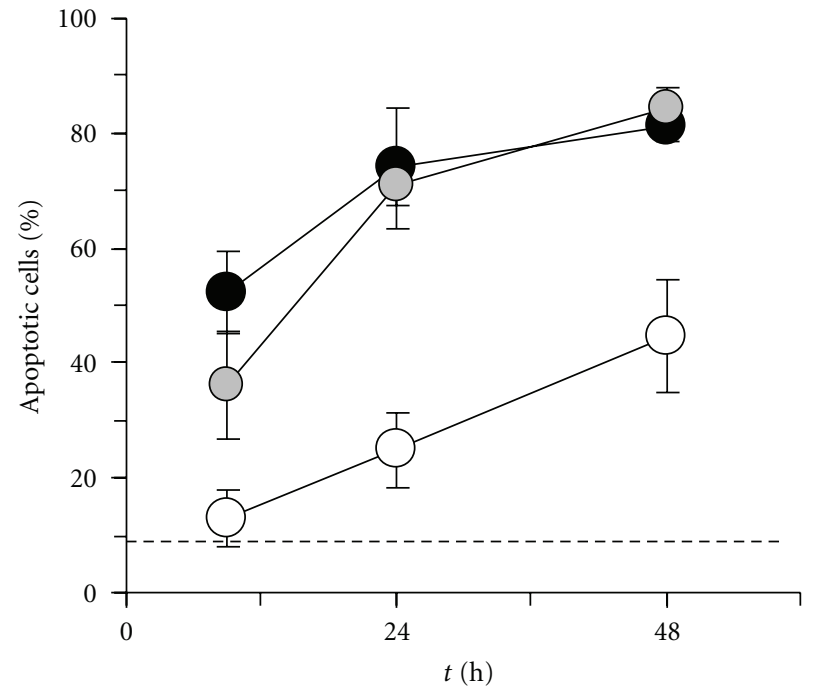

(a)

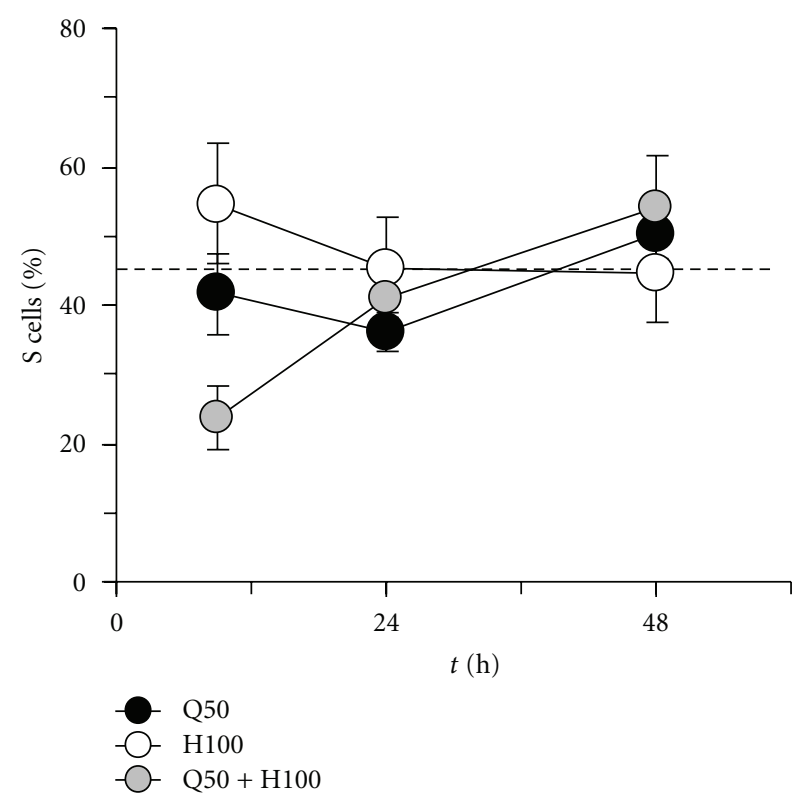

(c)

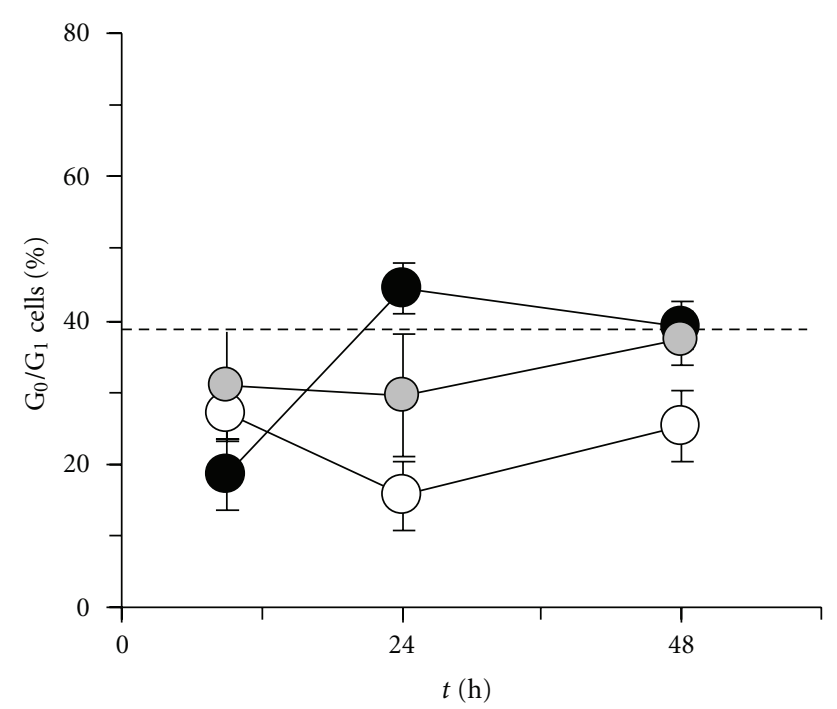

(b)

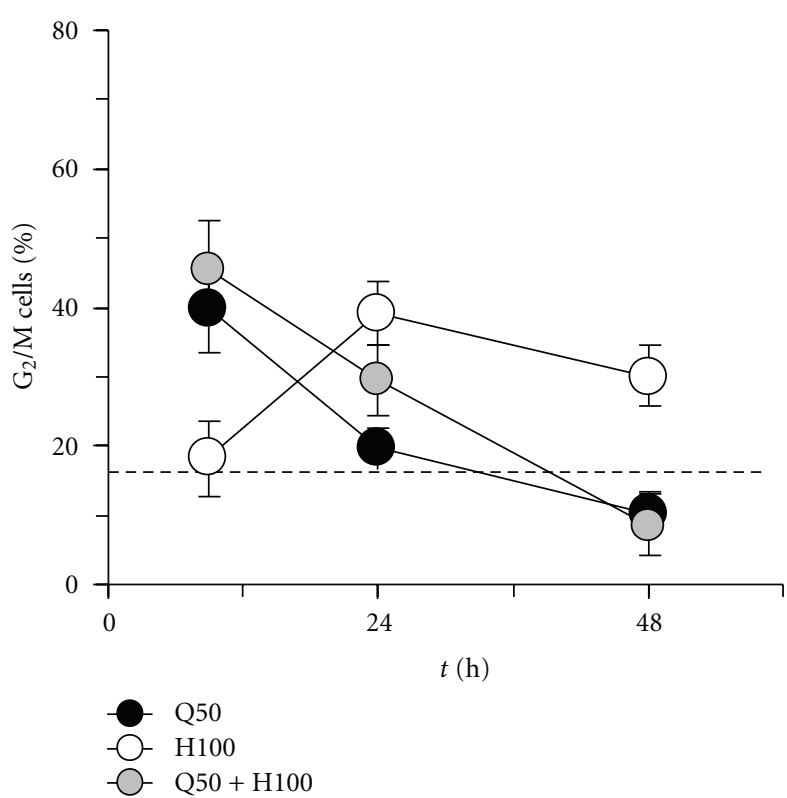

(d)

FIGURE 2: Time course of the apoptotic rate and cell-cycle distribution after treatment of Jurkat cells with $50 \mu \mathrm{M}$ QC for $24 \mathrm{~h}$ (Q50, solid circles), $100 \mu \mathrm{M} \mathrm{H}_{2} \mathrm{O}_{2}$ for $20 \mathrm{~min}$. (H100, open circles), or combination of the two (50 $\mu \mathrm{M}$ QC preincubation followed by addition of $100 \mu \mathrm{M}$ $\mathrm{H}_{2} \mathrm{O}_{2}$ for 20 min.; treatment denoted as Q50 + H100, gray circles). Apoptotic rates (a), $\mathrm{G}_{0} / \mathrm{G}_{1}(\mathrm{~b}), \mathrm{S}$ phase (c), and $\mathrm{G}_{2} / \mathrm{M}$ (d) cell fractions are indicated. The dashed line represents the average obtained from control cell samples.

Menadione also induced apoptosis dose and time dependently (Figure 1(a), Figure S1D). A relatively low dose of $25 \mu \mathrm{MMD}$ produced a consistent apoptotic rate when delivered for a long time $(4 \mathrm{~h}$, treatment "M $25 \times 4 \mathrm{~h}$ ") but not for a short interval (20 min., treatment "M25"). The highest dose used here, $250 \mu \mathrm{MMD}$ delivered for $20 \mathrm{~min}$. (treatment "M250"), produced large apoptotic cell fractions at 24 and $48 \mathrm{~h}$ after the treatment (Figure S1D) and decreased clonogenic survival of Jurkat cells to $12.3 \pm 3.6 \%$ $(n=4)$. A significant enhancement of apoptosis induced by $250 \mu \mathrm{M}$ MD was obtained by preincubating Jurkat cells with $5 \mu \mathrm{M}$ QC or $0.5 \mu \mathrm{M}$ EGCG for $24 \mathrm{~h}$, as well as with $10 \mu \mathrm{M}$ QC for $1 \mathrm{~h}$ but not with $0.5 \mu \mathrm{M}$ QC for $24 \mathrm{~h}$. In general, MD, alone or in combination with QC or EGCG, decreased the $\mathrm{G}_{0} / \mathrm{G}_{1}$ cell fraction and elevated to some extent the $\mathrm{S}$ cell fraction in the first $24 \mathrm{~h}$ after the treatment (Figures $1(\mathrm{~b})$ and $1(c))$. The $G_{2} / M$ cell fraction increased significantly in the treatments M25 $\times 4 \mathrm{~h}$ and M250, as well as in combination with a long preincubation $(24 \mathrm{~h})$ with very low doses of $0.5 \mu \mathrm{M}$ QC or EGCG (Figure 1(d)). $250 \mu \mathrm{M}$ MD applied alone for $20 \mathrm{~min}$. increased significantly the $\mathrm{G}_{2} / \mathrm{M}$ cell fraction from the control baseline of $15.7 \pm 4.5 \%$ to $22.5 \pm$ $4.3 \%$ in the first $24 \mathrm{~h}$ after the treatment (Figure $1(\mathrm{~d})$ ). The parallel decrease in the $G_{0} / G_{1}$ cell fraction (Figure 1(b)) and conservation of the S-phase distribution (Figure 1(c)) suggest that $M D$ did not affect $G_{0} / G_{1}$ and S-phase 
progression. However, during the subsequent $24 \mathrm{~h}$ the $\mathrm{G}_{2} / \mathrm{M}$ block was removed and the cell cycle distribution became similar to that of control cells. At variance with this result, a persistent $\mathrm{G}_{2} / \mathrm{M}$ arrest could be observed in cells treated with the low dose of $25 \mu \mathrm{M}$ MD for $4 \mathrm{~h}$. Furthermore, the cell cycle dynamics following this treatment suggest also a $\mathrm{G}_{0} / \mathrm{G}_{1}$ arrest that could lead to an apparently normal $\mathrm{G}_{0} / \mathrm{G}_{1}$ cell fraction and to a decline in the S-cell fraction at $48 \mathrm{~h}$ after the treatment. Similarly, in the EGCG-MD combination the $\mathrm{G}_{2} / \mathrm{M}$ blockage persisted even after $48 \mathrm{~h}$ following the treatment, when the $\mathrm{G}_{2} / \mathrm{M}$ cell fraction increased to $25.2 \pm$ $2.9 \%$. However, in this case the reduction of the $\mathrm{G}_{0} / \mathrm{G}_{1}$ cell pool and the conservation of the $\mathrm{S}$-cell fraction indicate that the $G_{0} / G_{1}$ and $S$ phases were not affected by this treatment.

Hydrogen peroxide acted as a potent inducer of apoptosis in Jurkat cells (Figures 1 and 2, Figure S1E). Interestingly, $100 \mu \mathrm{M} \mathrm{H} \mathrm{H}_{2} \mathrm{O}_{2}$ but not $500 \mu \mathrm{M} \mathrm{H} \mathrm{H}_{2} \mathrm{O}_{2}$ applied for 20 min. could increase significantly the $\mathrm{G}_{2} / \mathrm{M}$ cell fraction (Figure 1(d)), suggesting that the highest dose produced severe cell damage that inhibited the activation and/or the maintenance of the $\mathrm{G}_{2} / \mathrm{M}$ checkpoint. This conclusion was further supported by results obtained with cells exposed to $500 \mu \mathrm{M} \mathrm{H} \mathrm{H}_{2} \mathrm{O}_{2}$ after a $1 \mathrm{~h}$ preincubation with $10 \mu \mathrm{M}$ QC. These cells presented a greatly reduced apoptotic rate and a considerable blockage in the $\mathrm{G}_{2} / \mathrm{M}$ phase, as compared with the cells exposed to $500 \mu \mathrm{M} \mathrm{H}_{2} \mathrm{O}_{2}$ in the absence of $\mathrm{QC}$, indicating that QC exerted an antioxidant effect and protected cells against $\mathrm{H}_{2} \mathrm{O}_{2}$. Application of $100 \mu \mathrm{M} \mathrm{H}_{2} \mathrm{O}_{2}$ for $20 \mathrm{~min}$. after preincubation with $50 \mu \mathrm{M}$ QC for $24 \mathrm{~h}$ induced apoptosis in a manner that was closely similar to that produced by the quercetin treatment alone (Figure 2(a)). This effect was also observed for the $G_{2} / M$ cell fraction (Figure 2(d)). However, a significant difference was visible in the $G_{0} / G_{1}$ and $S$ cell pools $9 \mathrm{~h}$ after the treatment (Figures 2(b) and 2(c)), when the S-cell fraction exhibited a marked reduction, while the $G_{0} / G_{1}$ fraction did not change significantly. Together, these findings suggest that, beside the observed $\mathrm{G}_{2} / \mathrm{M}$ arrest, the combination of $\mathrm{QC}$ and $\mathrm{H}_{2} \mathrm{O}_{2}$ produced an additional blockage of the cell cycle in the $\mathrm{G}_{0} / \mathrm{G}_{1}$ phase as well, whereas the $S$ phase progressed normally. However, after $48 \mathrm{~h}$ the cell cycle distribution became similar to that produced by quercetin alone. A significant enhancement of apoptosis induced by $\mathrm{H}_{2} \mathrm{O}_{2}$ was obtained by preincubation with $0.5 \mu \mathrm{M}$ EGCG for $24 \mathrm{~h}$ (Figure 1), whereas a short incubation with $10 \mu \mathrm{M}$ QC for $1 \mathrm{~h}$ exerted protective effects against $\mathrm{H}_{2} \mathrm{O}_{2}$, consistent with earlier findings $[15,27]$. Thus, the apoptotic cell fraction produced by $500 \mu \mathrm{M} \mathrm{H}_{2} \mathrm{O}_{2}$ decreased 3 times, and this process was correlated with a consistent $\mathrm{G}_{2} / \mathrm{M}$ block (Figure 1), indicating that the short preincubation with quercetin can protect cells against the deleterious effects of $\mathrm{H}_{2} \mathrm{O}_{2}$ and improve the cell capacity of repair.

In treatments with duration of $1 \mathrm{~h}, \mathrm{QC}$ decreased clonogenic survival in an exponential manner, with an estimated dose for reduction of clonogenicity to $50 \%, D_{50 \%}=109.8 \mu \mathrm{M}$ (Figure 3(a)). In separate spectrofluorimetry experiments, $\mathrm{QC}$ also decreased the cellular content of $\mathrm{NAD}(\mathrm{P}) \mathrm{H}$ in a dose-dependent manner, with an effective dose for halfmaximal effect $\mathrm{IC}_{50}=39.5 \mu \mathrm{M}$ (Figure 3(b)). In Figure 3(c) we present some examples of $\mathrm{NAD}(\mathrm{P}) \mathrm{H}$ fluorescence recordings in Jurkat cell suspensions exposed to different concentrations of QC. After addition of QC, the NAD $(\mathrm{P}) \mathrm{H}$ fluorescence signal decreased slowly (in up to $\sim 15 \mathrm{~min}$.) to a steady value which appeared to be dose dependent. Figure 3(b) summarizes the steady state data obtained from recordings like those in Figure 3(c).

In a different set of experiments, we investigated the effects of preincubating Jurkat cells with $50 \mu \mathrm{M}$ QC for $1 \mathrm{~h}$ on apoptosis and cell cycle distribution after irradiation with 2 Gy of protons (Figure 4, Figure S1F). Quercetin exercised an inhibitory effect on apoptosis (Figure 4(a), Figure S1F) and appeared to prolong significantly the $\mathrm{G}_{2} / \mathrm{M}$ arrest induced by proton irradiation (Figure 4(d)), which may indicate an enhanced capacity for DNA repair and maintenance of the $\mathrm{G}_{2} / \mathrm{M}$ checkpoint active. The parallel reduction in the $\mathrm{S}$-cell pool (Figure $4(\mathrm{c})$ ) and conservation of the $\mathrm{G}_{0} / \mathrm{G}_{1}$ cell fraction (Figure $4(\mathrm{~b})$ ) suggests that cells surviving irradiation may experience an additional $\mathrm{G}_{0} / \mathrm{G}_{1}$ but not S-phase arrest after $48 \mathrm{~h}$ from irradiation.

\subsection{Effects of Proton Radiation, $\mathrm{MD}, \mathrm{H}_{2} \mathrm{O}_{2}$, QC, and EGCG on} Delayed Luminescence. Delayed luminescence of control cells presented a multiscale kinetics (Figure 5(a)) which could be fitted very well by a linear combination of seven exponential components (not shown). In addition to collecting all photons emitted in the entire visible domain, DL could be also measured at emission wavelengths of $460 \mathrm{~nm}$ and $645 \mathrm{~nm}$, respectively, by using selective filters. Photoemission at these two wavelengths exhibited kinetic profiles that were qualitatively similar to that obtained in the visible domain. The intensity of emitted red light was consistently higher than the intensity of emitted blue light in the time domain $10-100 \mu$ s and was closely similar to that of blue light in the time domain $100 \mu \mathrm{s}-100 \mathrm{~ms}$.

DL of Jurkat cells irradiated with 10 Gy of high-energy protons exhibited different characteristics when probed at $1 \mathrm{~h}$ or $24 \mathrm{~h}$ after irradiation. Hence, a reduction of $34.1 \pm 9.6 \%$ in the DL-III relative quantum yield in VIS was observed after $1 \mathrm{~h}$ from irradiation, whereas the cell samples probed at $24 \mathrm{~h}$ after irradiation exhibited an increase of $27.3 \pm 8.5 \%$ in the DL-II relative quantum yield and an increase of $41.8 \pm$ $14.3 \%$ in the time domain $10-100 \mathrm{~ms}$, while all the other components of the DL emission in VIS were not significantly different from the resting DL emission (Figure 5(b)). Shortly after irradiation, DL emitted at $460 \mathrm{~nm}$ was similar to that of control cells; however, the surviving cells exhibited $24 \mathrm{~h}$ later a significant overall DL enhancement with about $35 \%$ of the control intensity (Figure 5(c)). A remarkable augmentation, up to $\sim 1.7$-fold, of blue light emission was detected for a DL component with an established time constant of $178 \mu \mathrm{s}$ (value derived from fitting analysis, not shown; however, the distinctive peak centered on $\sim 180 \mu$ s is clearly visible in Figure $5(\mathrm{c})) .1 \mathrm{~h}$ after irradiation, delayed emission of red light presented a significant reduction of the DL-III component, with $38.3 \pm 11.5 \%$, whereas $24 \mathrm{~h}$ later DL-I decreased to $76.1 \pm 13.8 \%$ of control emission, and there was a significant increase of a DL component with an estimated time constant of $379 \mu$ s (Figure 5(d), and data analysis not shown). 


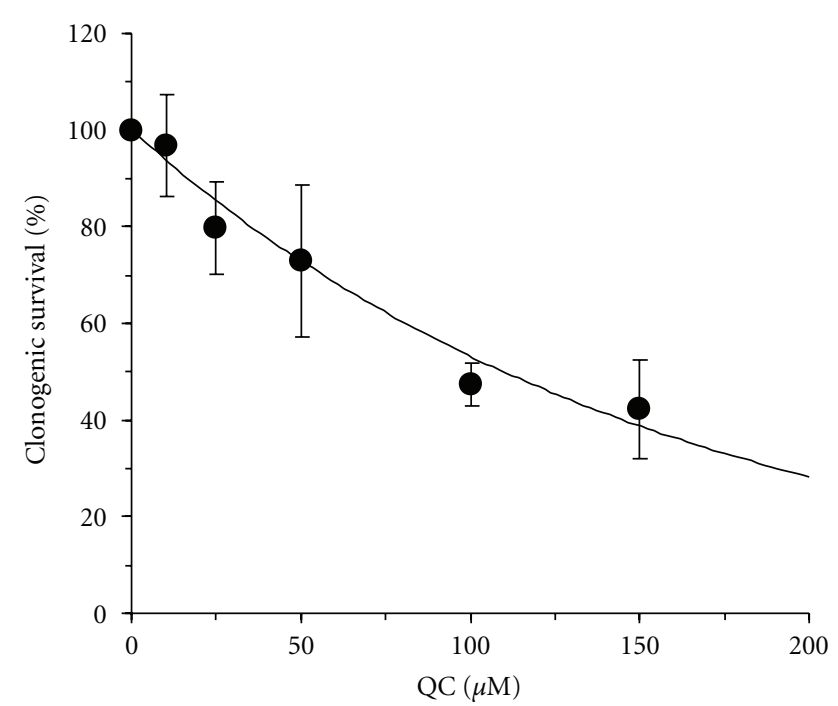

(a)

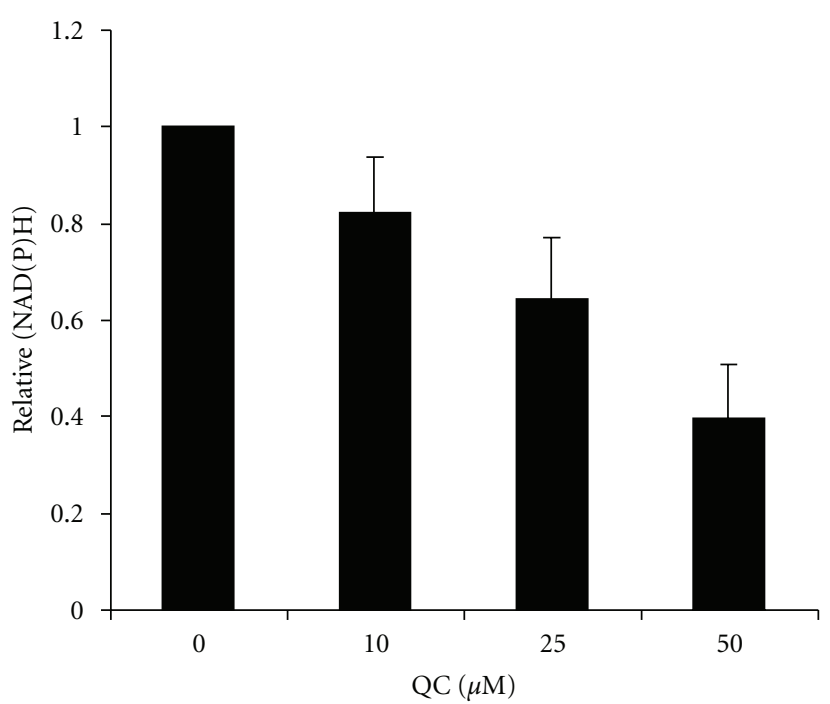

(b)

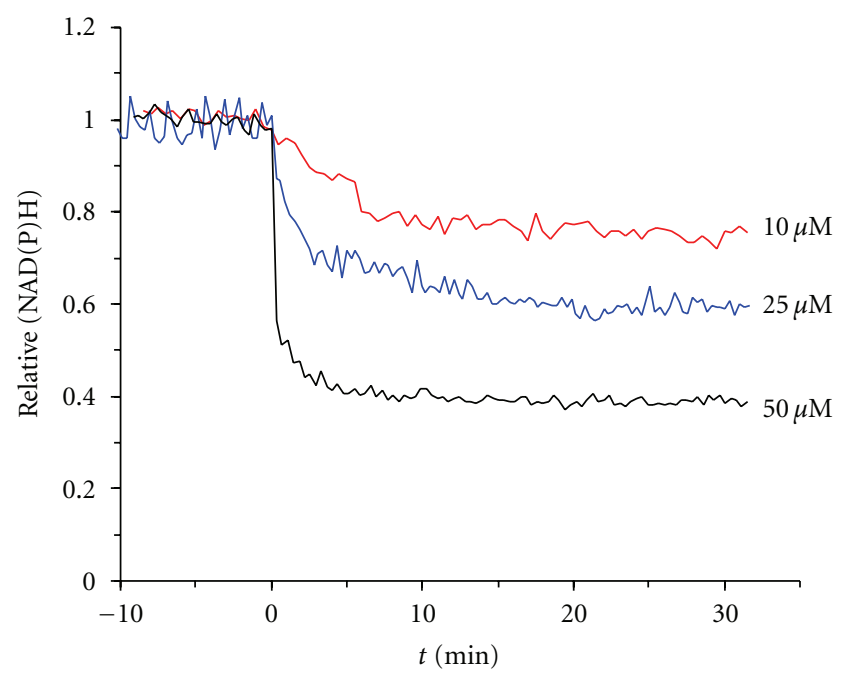

(c)

FIGURE 3: Quercetin decreases clonogenic survival and the cellular content of NAD(P)H in Jurkat cells. (a) Dose response of clonogenicity $(S)$ was fitted to an exponential function (curve) of the form $S(\%)=100 \times \exp \left(-D / D_{0}\right)$, where $D$ represents the dose of QC applied for $1 \mathrm{~h}$ and the characteristic dose derived from the fit was $D_{0}=158.5 \mu \mathrm{M}$. Data are expressed as mean \pm standard deviation of $4-6$ separate determinations. (b) The ratio between NAD $(\mathrm{P}) \mathrm{H}$ fluorescence of treated versus control cells (relative NAD(P)H) obtained in steady state after addition of QC to cell suspensions decreases with the level of QC. (c) Representative recordings of NAD(P)H fluorescence relative to the resting value in cell suspensions before and after addition of QC at various levels indicated near each trace.

At increasing doses, quercetin inhibited DL progressively (Figure 6(a)). The most sensitive DL region was DL-III, which decreased by one order of magnitude after the treatment with $50 \mu \mathrm{M}$ QC for $24 \mathrm{~h}$, whereas DL-I was only slightly affected by QC. EGCG exerted a qualitatively different effect on DL by producing a fairly uniform reduction of the photoemission intensity along the entire timescale.

$500 \mu \mathrm{M} \mathrm{H}_{2} \mathrm{O}_{2}$ applied for 20 min. reduced DL significantly over the regions DL-I and DL-II (Figures 6(b), 7(a) and $7(\mathrm{~b}))$. Pretreatment with $0.5 \mu \mathrm{M}$ EGCG for $24 \mathrm{~h}$ was able to induce a significant recovery of DL-II emission, whereas preincubation with $10 \mu \mathrm{M}$ QC for $1 \mathrm{~h}$ further reduced the DL-III intensity. The lower dose of $100 \mu \mathrm{M} \mathrm{H}_{2} \mathrm{O}_{2}$ had a modest effect on DL and inhibited photoemission by $\approx 22 \%$ over the entire timescale (Figures $7(a)-7(c)$ ). Preincubation with $50 \mu \mathrm{M}$ QC for $24 \mathrm{~h}$ restored DL-I emission but inhibited substantially DL-II and DL-III.

Menadione also inhibited DL in a dose-dependent manner. In addition, at variance with the modest effect of QC on DL-I, MD reduced substantially photoemission in the DL-I region (Figure 7(a)). This inhibition was strong even at the lowest dose of $25 \mu \mathrm{M}$ menadione. DL-II was inhibited to a similar extent by high doses of MD (Figure 7(b)), whereas DL-III exhibited a drastic reduction and thus, in the M250 treatment, the DL-III quantum yield reached $15.5 \pm 6.1 \%$ of its resting value (Figure $7(\mathrm{c})$ ). Preincubation with the two 


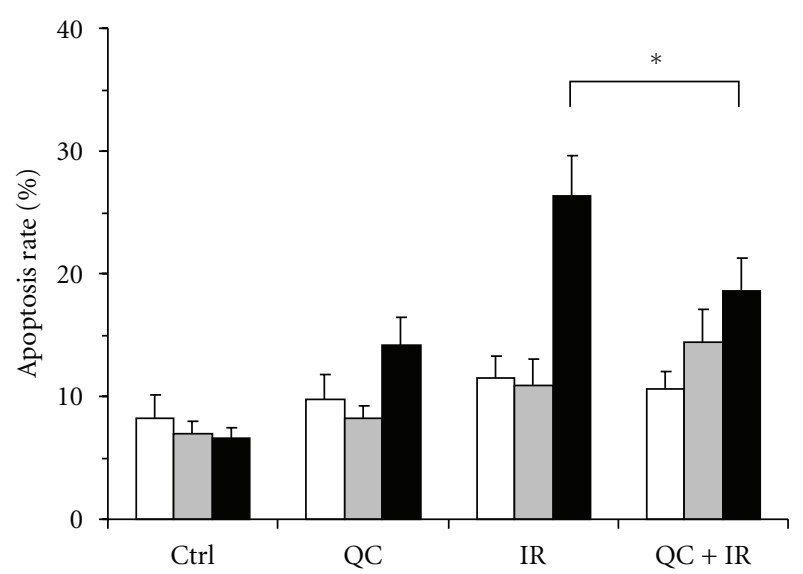

(a)

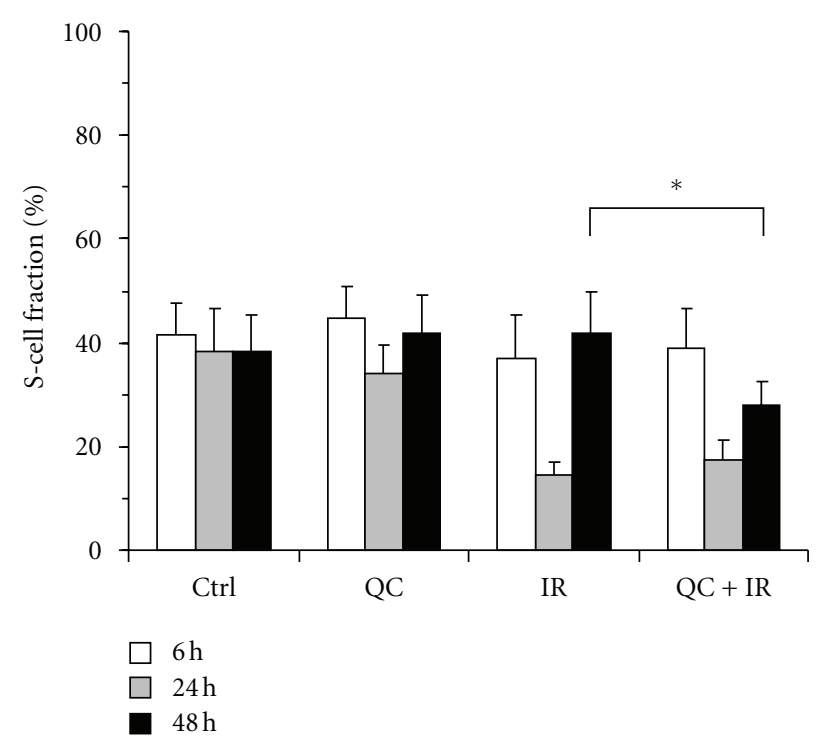

(c)

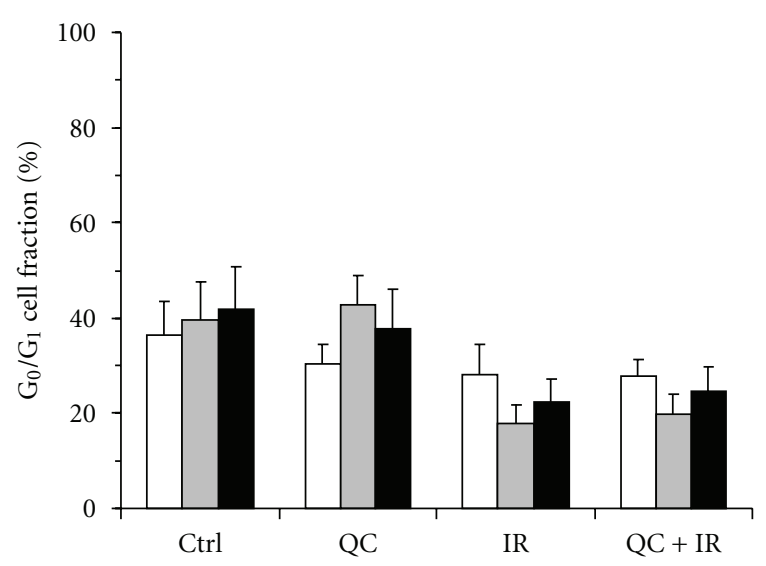

(b)

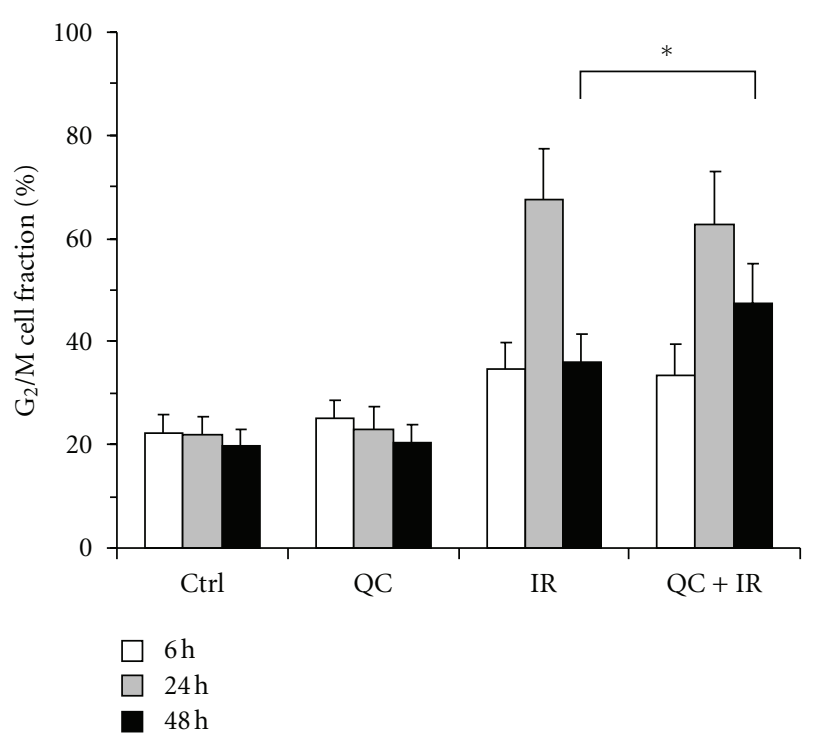

(d)

FIGURE 4: Apoptosis and cell-cycle distributions assessed at 6, 24, and $48 \mathrm{~h}$ after treatment of Jurkat cells with the vehicle (Ctrl), with $50 \mu \mathrm{M}$ QC for $1 \mathrm{~h}$ (QC), with $2 \mathrm{~Gy}$ of proton radiation (IR), or with $2 \mathrm{~Gy}$ of proton radiation after preincubation with $50 \mu \mathrm{M}$ QC for $1 \mathrm{~h}(\mathrm{QC}+\mathrm{IR})$. Apoptotic rates (a), $\mathrm{G}_{0} / \mathrm{G}_{1}(\mathrm{~b})$, S-phase (c), and $\mathrm{G}_{2} / \mathrm{M}$ (d) cell fractions are illustrated. The star denotes significant difference between the treatments: IR and QC + IR.

flavonoids generally induced partial recovery of DL-III up to $\sim 25 \%$ of the resting value, except in the case of pretreatment with $5 \mu \mathrm{M}$ QC for $24 \mathrm{~h}$, when a further reduction to $9.2 \pm$ $3.8 \%$ was recorded.

With treatments of varying time and dosage of two oxidative stress inducers, $\mathrm{MD}$ and $\mathrm{H}_{2} \mathrm{O}_{2}$, and two flavonoids, QC and EGCG, as well as irradiation with high-energy protons, we obtained a significant anticorrelation $\left(r_{\text {all }}=-0.61\right)$ between apoptosis and DL-II (Figure 7(e)). Notably, all MD treatments (with MD applied alone or in combination with QC or EGCG) alongside the radiation treatment were associated with a strong anticorrelation between DL-I, DL-II or DL-III, and apoptosis $\left(r_{\mathrm{M} / \mathrm{MQ} / \mathrm{ME} / \mathrm{IR}}=-0.76,-0.98\right.$ and -0.84 , resp.) (Figures $7(\mathrm{~d})-7(\mathrm{f})$ ). Furthermore, by selecting only treatments with $\mathrm{MD}, \mathrm{QC}$, and combinations of the two, we obtained a very strong anticorrelation between DL-II, or DL-III and apoptosis $\left(r_{\mathrm{M} / \mathrm{Q} / \mathrm{MQ}}=-0.91\right.$ and -0.82 , resp. $)$.

\section{Discussion}

At the moment, the effects of QC or EGCG on apoptosis induced in Jurkat $\mathrm{T}$ cells by the flavonoids themselves or in conjunction with menadione and hydrogen peroxide are poorly known. It is widely recognized that after intake, flavonoids like QC and EGCG exhibit an overall poor bioavailability, as they are rapidly metabolized and their levels in the plasma remain below $10 \mu \mathrm{M}[8,45]$. However, the content of active flavonoids can increase considerably in human tissues, in particular at the inflammatory sites. In vitro studies have shown that in human normal lymphocytes, high levels of $50 \mu \mathrm{M}$ QC can increase considerably the cellular content of $\mathrm{O}_{2}{ }^{-}$and $\mathrm{OH}^{\bullet}$ within $30 \mathrm{~min}$. of treatment [9]. Here we found that a 24-hour treatment with physiological levels $(0.5-5 \mu \mathrm{M})$ of QC and EGCG can potentiate the antiproliferative activity of menadione by enhancing 


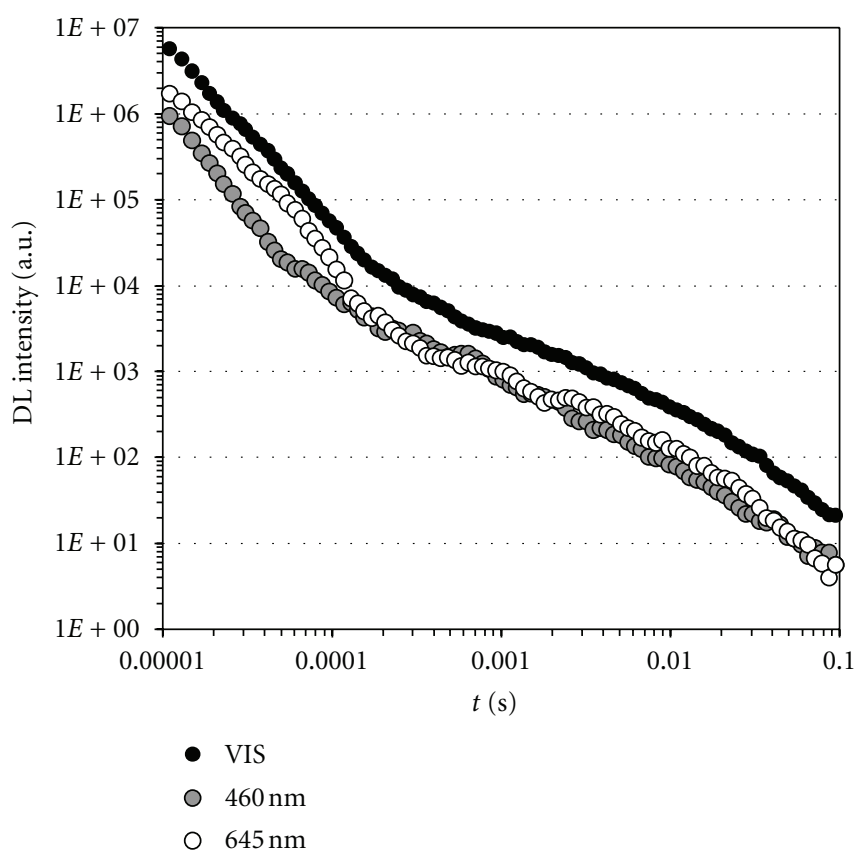

(a)

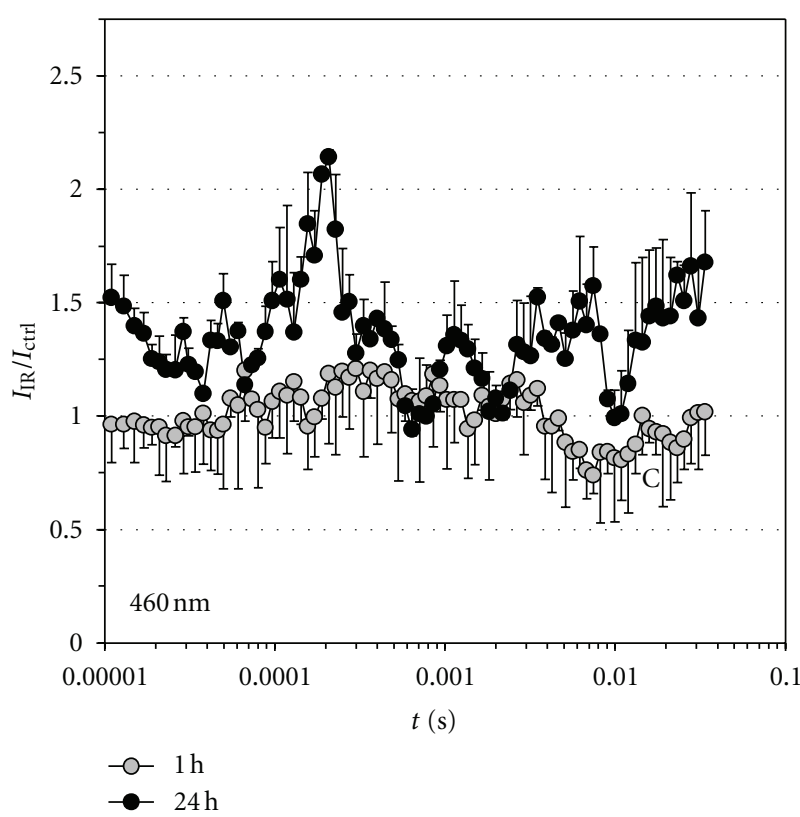

(c)

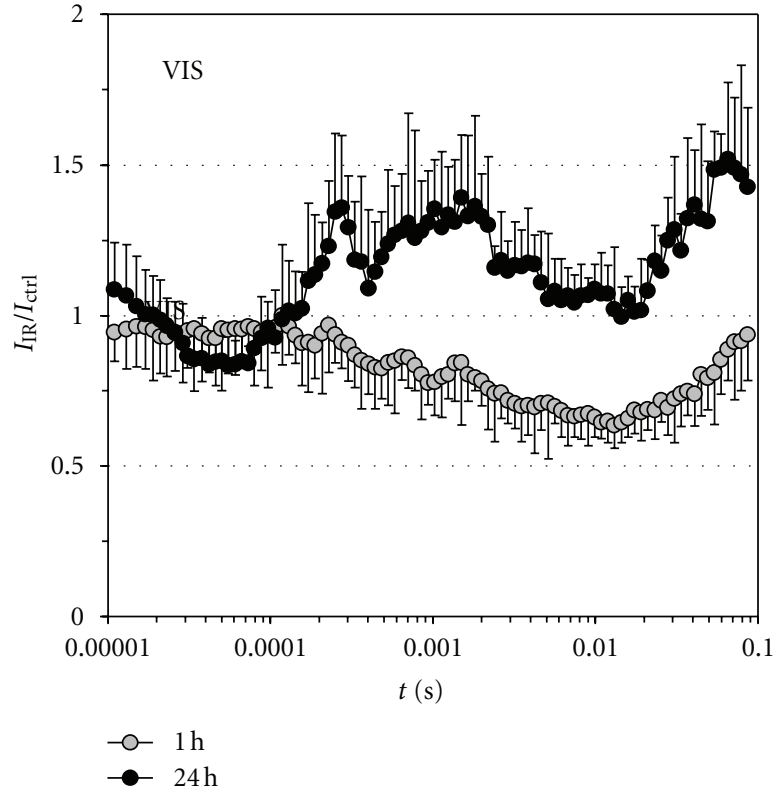

(b)

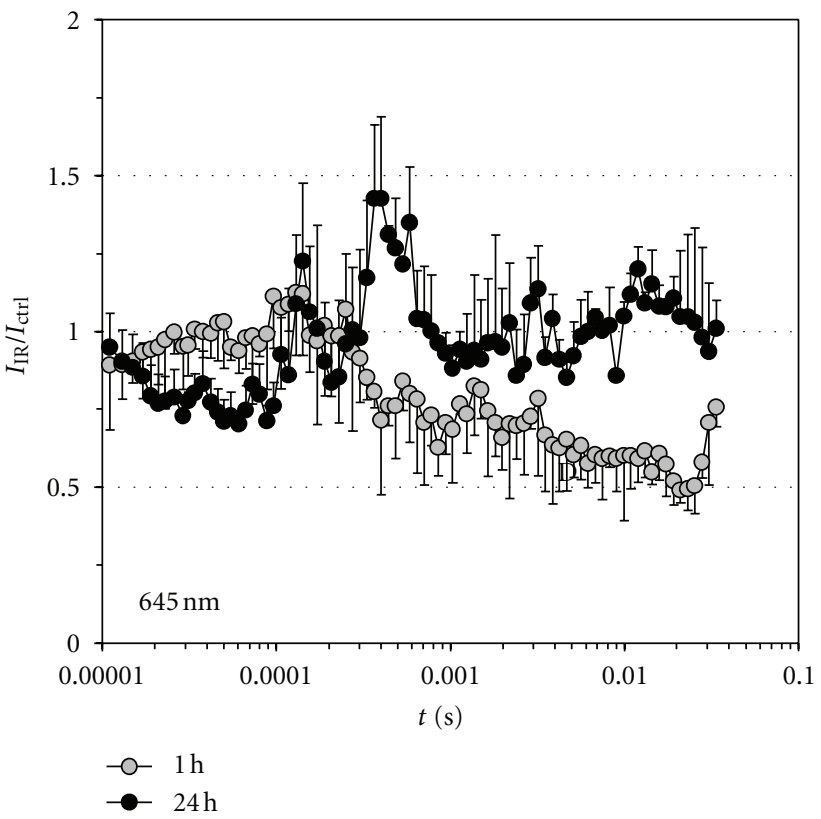

(d)

FIGURE 5: Kinetics of DL emission of Jurkat cells under control conditions (a) or after irradiation with 10 Gy of protons (b-d). In (a) some representative photoemission curves are shown for the entire visible domain (VIS), as well as for detection of $460 \mathrm{~nm}$ and $645 \mathrm{~nm}$ light emitted by the same cell sample. In (b-d) the intensity of light emission of irradiated cells $\left(I_{\mathrm{IR}}\right)$ is normalized to the DL intensity of sham-irradiated cultures $\left(I_{\mathrm{Ctrl}}\right)$. Measurements were done after $1 \mathrm{~h}$ and $24 \mathrm{~h}$ from irradiation, as indicated. Results are presented for VIS (b), $460 \mathrm{~nm}$ (c), and $645 \mathrm{~nm}$ (d) emitted light.

drug-induced apoptosis in human leukemia Jurkat T cells. In agreement with previous reports that QC is a more potent inhibitor of hydroxyl radical formation than a scavenger of superoxide anions [46], none of the quercetin-based treatments used in the present work exercised protective effects against MD, whereas a short incubation with $10 \mu \mathrm{M}$
QC for $1 \mathrm{~h}$ offered consistent protection against $\mathrm{H}_{2} \mathrm{O}_{2}$ and induced $\mathrm{G}_{2} / \mathrm{M}$ cell cycle arrest, hence allowing time for repair of $\mathrm{H}_{2} \mathrm{O}_{2}$-induced damage. In addition, preincubation for $24 \mathrm{~h}$ with a very low level $(0.5 \mu \mathrm{M})$ of EGCG increased significantly the $\mathrm{G}_{2} / \mathrm{M}$ cell fraction after exposure to $250 \mu \mathrm{M}$ MD. Nevertheless, albeit long-term administration of QC 


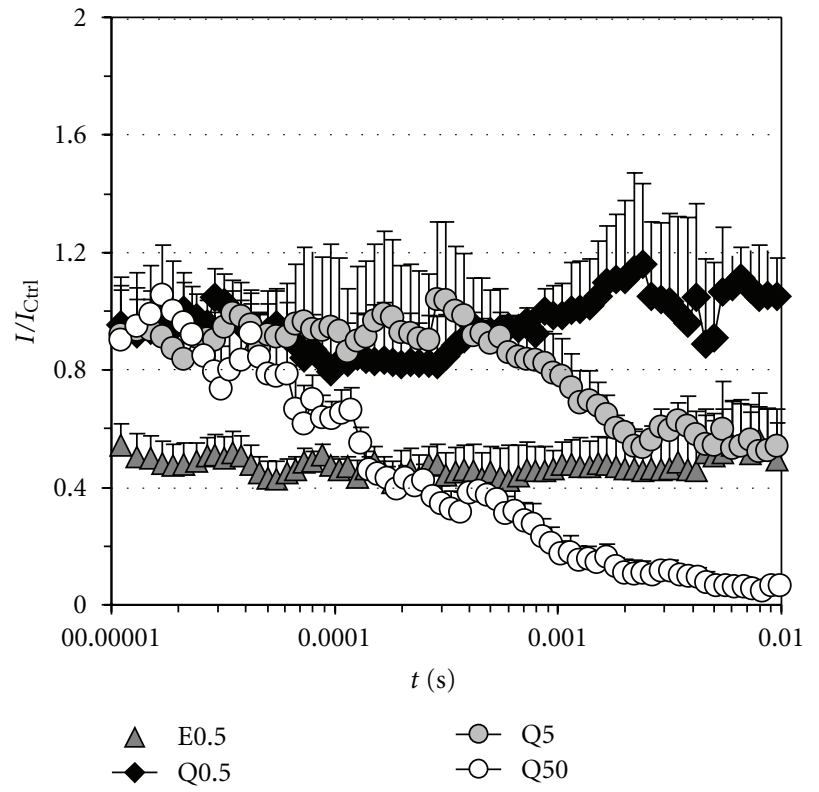

(a)

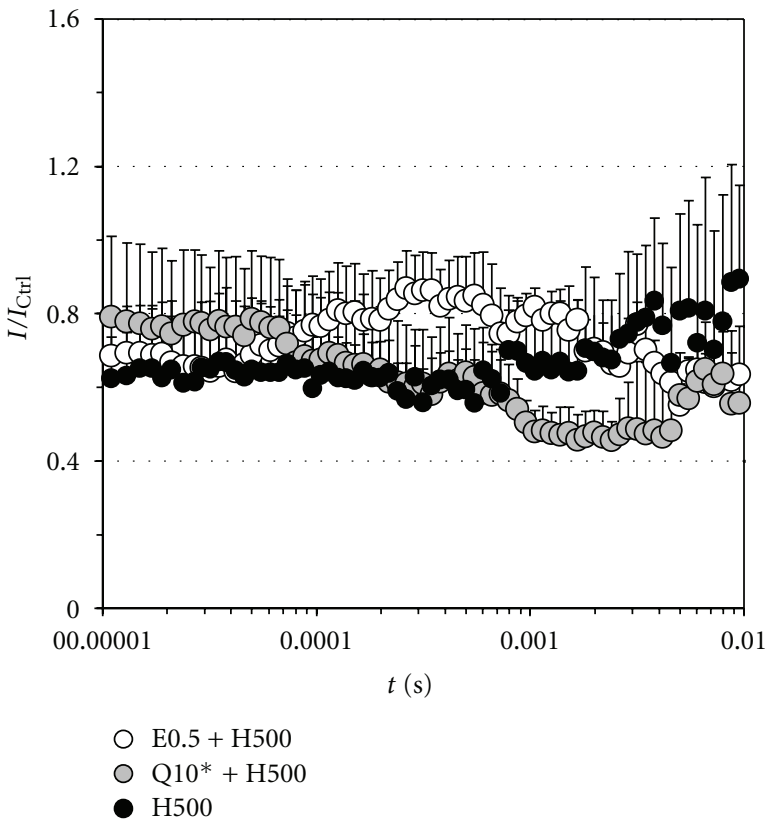

(b)

Figure 6: Kinetics of DL emission of Jurkat cells after various treatments with flavonoids (a) or with $\mathrm{H}_{2} \mathrm{O}_{2}$ alone or in combination with EGCG or QC (b). Treatments are labeled as in Figure 1. The intensity of light emission of treated cells $(I)$ is normalized to the DL intensity of control cells $\left(I_{\mathrm{Ctrl}}\right)$.

or EGCG may improve significantly the menadione-based treatment of leukemia, it is important to establish the critical level of flavonoid that is no longer beneficial to normal cells.

To our knowledge, there are only few reports (e.g., [47]) regarding the effects of quercetin on clonogenic survival, which may be a critical indicator for the antiproliferative efficiency of anti-cancer drugs as well as for the likelihood of relapse after chemotherapy. While short-term treatments ( $1 \mathrm{~h}$ here) with up to $50 \mu \mathrm{M}$ QC appeared to be effective in protecting Jurkat cells against $\mathrm{H}_{2} \mathrm{O}_{2}$ or proton irradiation, clonogenicity decreased considerably at higher doses of the flavonoid, with an estimated dose $D_{50 \%}=109.8 \mu \mathrm{M}$. Our investigations suggest a connection between the ability of quercetin to decrease the level of $\mathrm{NAD}(\mathrm{P}) \mathrm{H}$ and the induction of apoptosis, which is probably mediated by the failure to maintain the ATP-dependent electrochemical gradient across the inner mitochondrial membrane and the consequent dissipation of the mitochondrial membrane potential. The mechanism by which QC decreases the cellular content of $\mathrm{NAD}(\mathrm{P}) \mathrm{H}$ is unclear, since some early studies reported that QC can inhibit mitochondrial respiration [12], so we expected to observe an increase rather than a decrease in the $\mathrm{NAD}(\mathrm{P}) \mathrm{H}$ level. However, recent investigations based on different assays have indicated that QC can bind with high affinity to Complex I without inhibiting it [48] and can also stimulate mitochondrial respiration $[10,11]$. So, it is likely that under our experimental conditions, QC actually stimulated the activity of Complex I in Jurkat cells and thus led to an increased rate of NADH consumption as a substrate for Complex I.

Interestingly, we found that $100 \mu \mathrm{M} \mathrm{H} \mathrm{H}_{2} \mathrm{O}_{2}$ but not $500 \mu \mathrm{M} \mathrm{H}_{2} \mathrm{O}_{2}$ applied for $20 \mathrm{~min}$. could increase significantly the $G_{2} / M$ cell fraction, suggesting that the higher dose of the oxidant agent produced more severe cell damage that inhibited the activation and/or the maintenance of the $G_{2} / M$ checkpoint. A similar interesting outcome of our studies regarding the cellular effects of high-energy protons is that a higher dose (10 Gy here) of radiation could produce more damage to the apoptotic apparatus and could also reduce the capacity for DNA repair as compared with a lower dose ( 2 Gy here). At variance with this interpretation, an increase of $\sim 12 \%$ in the apoptotic rate at $24 \mathrm{~h}$ after irradiation with $10 \mathrm{~Gy}$ of gamma rays was reported [29]. Moreover, it has been found that high doses ( $\geq 10 \mathrm{~Gy}$ ) of $\mathrm{X}$ or $\gamma$ radiation can induce significant apoptosis in Jurkat cells, in a timeand dose-dependent manner $[25,29,30]$, which is in marked contrast with our findings. We then addressed this issue in a different cell type. Remarkably, in a B-lymphocyte cell line irradiated with 2 and 5 Gy of protons, respectively, the apoptotic rate and the cell-cycle distribution obtained after irradiation of these cells were qualitatively similar to those observed with Jurkat cells (not shown). Taken together, all these findings support the notion that, in comparison with the $\mathrm{X}$ or $\gamma$ radiation, larger doses of high-energy protons produce more clusters of ionizations, which lead to more severe damage to the apoptotic or the cell cycle machinery.

Similarly to the protective effect of QC against $\mathrm{H}_{2} \mathrm{O}_{2}$ discussed above, our results suggest that short treatments with quercetin could be able to improve cell survival after proton irradiation, most likely by inhibiting hydroxyl radical formation after irradiation and protecting against cellular oxidative DNA damage. However, the fact that high-energy protons produce cellular lesions predominantly via direct ionizations, not ROS formation, together with our findings 


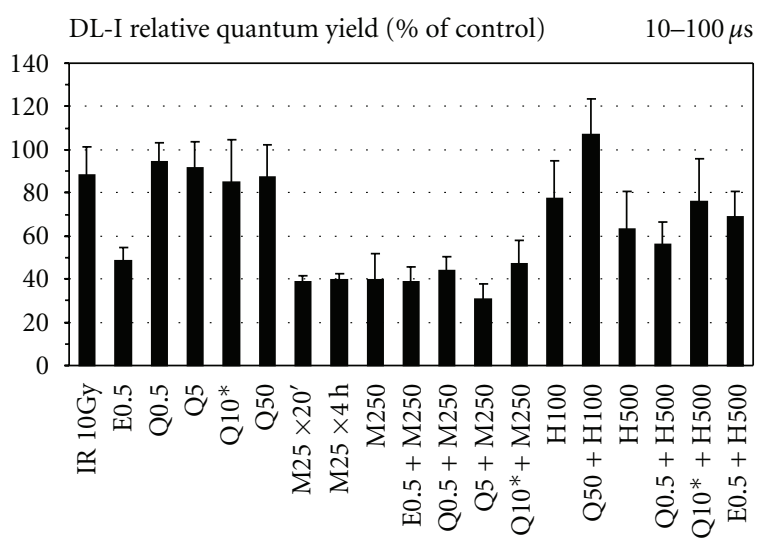

(a)

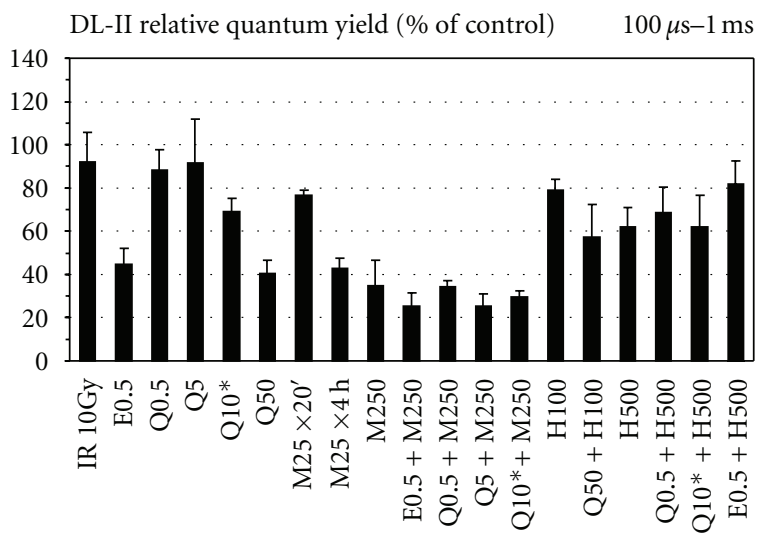

(b)

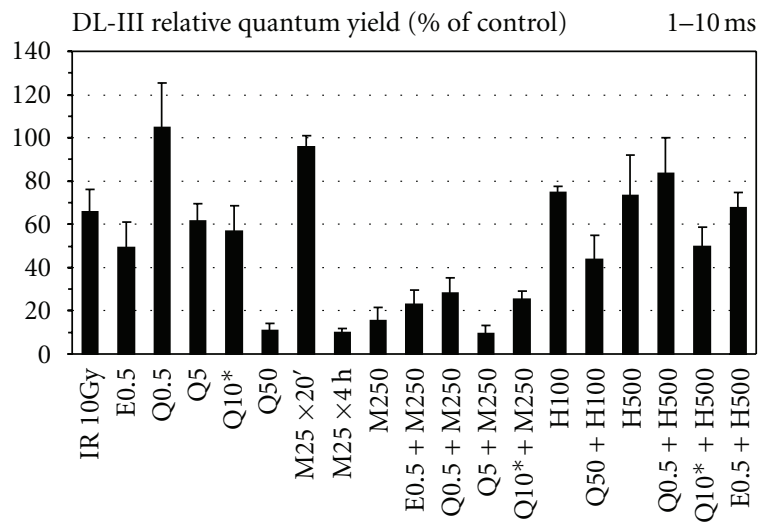

(c)

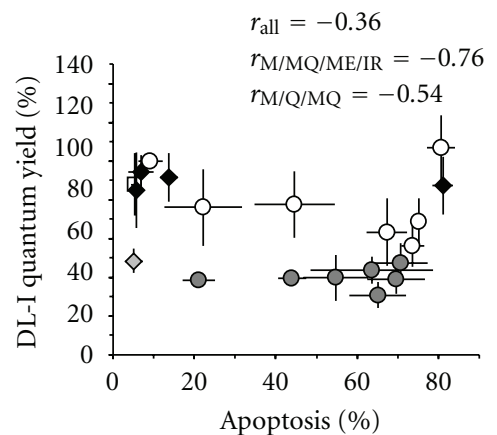

(d)

$r_{\text {all }}=-0.61$

$r_{\mathrm{M} / \mathrm{MQ} / \mathrm{ME} / \mathrm{IR}}=-0.98$

$r_{\mathrm{M} / \mathrm{Q} / \mathrm{MQ}}=-0.92$

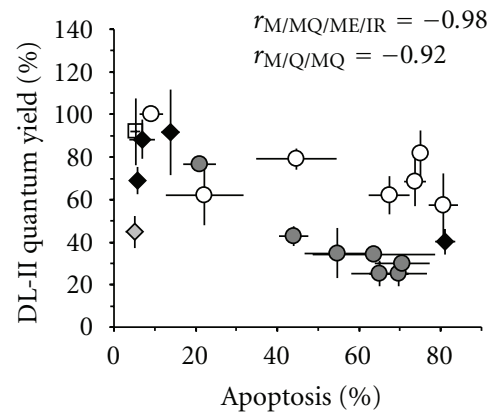

(e)

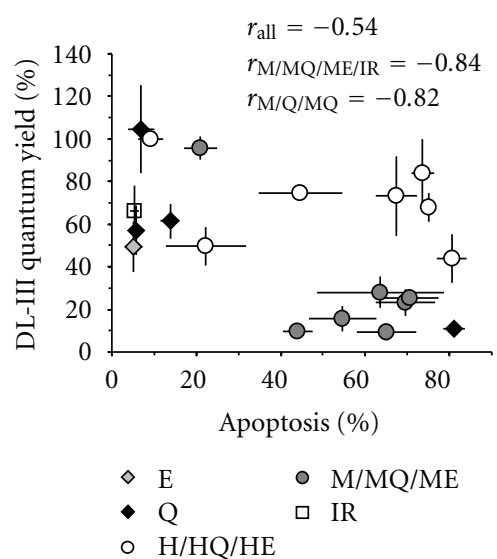

(f)

Figure 7: DL-quantum yield relative to control $(\mathrm{a}-\mathrm{c})$ and its correlation to the apoptotic cell fraction (d-f) under various treatments indicated in Figure 1. Q, E, M/MQ/ME, H/HQ/HE, and IR denote single QC or EGCG treatments, MD treatments with or without QC or EGCG preincubation, $\mathrm{H}_{2} \mathrm{O}_{2}$-treatments with or without QC or EGCG preincubation, and irradiation with 10 Gy of protons, respectively. Pearson correlation coefficients are shown for all treatments $\left(r_{\text {all }}\right)$, for the M/MQ/ME/IR treatments $\left(r_{\mathrm{M} / \mathrm{MQ} / \mathrm{ME} / \mathrm{IR}}\right)$ and for the M/Q/MQ treatments $\left(r_{\mathrm{M} / \mathrm{Q} / \mathrm{MQ}}\right)$. Results obtained for separate DL time domains indicated inside boxes are displayed individually for DL-I (a, d), DL-II $(\mathrm{b}, \mathrm{e})$, and DL-III $(\mathrm{c}, \mathrm{f})$.

that the protective effects of quercetin against proton-irradiation were relatively modest, suggests that quercetin may not be able to protect against the formation of the more severe lesions induced by clustered ionizations.

Our studies offer novel insights into the relationship between the cell status and delayed luminescence. In biological systems, DL may be generated by direct emitters like flavins, carbonyl derivatives, and aromatic compounds, by molecular oxygen and its various species, by the DNA or the cytoskeleton, as well as by collective molecular interactions, for example, triplet-triplet annihilation, electric field effects in membranes [31-40]. Previous data from our laboratories have indicated an important role of the mitochondrial Complex I in DL [15], consistent with earlier findings that 
some electron transport inhibitors can reduce light emission by mitochondria and chloroplasts [41-43]. In Complex I, the two electrons delivered by reduced nicotinamide adenine dinucleotide (NADH) to flavine mononucleotide (FMN) are transferred between eight consecutive iron-sulfur clusters, eventually reaching the ubiquinone. Our earlier findings [15] suggested that upon UV irradiation, FMN can produce excited singlet states that may either decay to the ground state by prompt fluorescence [49] or undergo intersystem crossing to long-lived triplet states [50] which can subsequently relax to some metastable intermediate states [50]. These triplet- or metastable-state species exhibit an intrinsically long lifetime, allowing a series of photochemical reactions to occur in Complex I via charge recombination in the $\mathrm{Fe} / \mathrm{S}$ redox centers and then produce secondary excitations, hence giving rise to delayed luminescence.

The data presented here indicate that DL of protonirradiated cells probed shortly after irradiation was dominated by light emission in the red region of the spectrum and was characterized by a significant reduction in the millisecond DL-III region. On the contrary, DL emission of irradiated cells that survived the subsequent $24 \mathrm{~h}$ was dominated by light emission in the blue region of the spectrum and exhibited a significant increase in the submillisecond DL-II region. Moreover, cells that survived 1 day postirradiation revealed two distinctive DL states, namely, a blue-light emitting state with a characteristic lifetime of $178 \mu \mathrm{s}$ and a red-light emitting state with a characteristic lifetime of $379 \mu \mathrm{s}$. In agreement with our previous results [15] and a series of data we have obtained with rotenonetreated cells (not shown), as well as with established electron transfer rates within Complex I [51], we propose that the red-light emitting state is characteristic to the $\mathrm{Fe} / \mathrm{S}$ center $\mathrm{N} 2$ in reduced form. Given the value of the characteristic lifetime of the blue-light emitting state, it is likely that this state is connected to the other extreme Fe/S center, namely, N1a, which has a similar time constant for its reduction rate [51]. In addition, the DL-III region may reflect the reduction kinetics of the remaining redox centers of Complex I that reside between the two extreme N1a and N2 centers, which have been determined to exhibit a slow reduction on the millisecond scale [51]. Accordingly, our data suggest that immediately after irradiation there is a significant decline in the pool of reduced intermediary Fe/S centers, whereas after $24 \mathrm{~h}$ there is a significant increase in the pool of reduced N1a and N2 centers. It means that on short-term high-energy protons can disrupt the electron transfer within Complex I, either by lowering the cellular content of NADH (directly and/or indirectly) and thus decreasing the availability of $\mathrm{NADH}$ for binding to Complex I or by directly altering the structure or the functionality of Complex I. However, surviving cells appear to regain functionality of Complex I within one day from irradiation, yet manifesting a partial inhibition at the level of the centers N1a and N2.

We found previously that $\mathrm{QC}$ and $\mathrm{MD}$ at high doses exhibited virtually identical effects on DL over a wide time interval, from $100 \mu$ s to $10 \mathrm{~ms}$ after laser excitation [15], probably due to their similar action at the level of Complex I. After measuring superoxide production at Complex I by menadione, $\mathrm{Xu}$ and Arriaga concluded that Complex I may accept an electron from menadione at a specific site of Complex I [52]. Our results obtained by DL spectroscopy suggest an equivalent action of $\mathrm{MD}$ and $\mathrm{QC}$ at the level of the Fe/S center N2, which may be mediated by the binding of each of these molecules to a common site in Complex I. Having in view the structural similarity between QC and rotenone, it is most likely that the QC/MD site is the rotenone-binding site itself [48], which resides near the center N2 and thus allows the bound molecule of rotenone to hinder the electron transfer from N2 to ubiquinone.

The faster DL region, DL-I, exhibited the most variable response to our treatment conditions. QC and proton irradiation did not affect DL-I, while MD and EGCG reduced consistently DL-I even at low doses. Taking into consideration all the results presented here, we suppose that DLI may be associated with the photoemission characteristics of FMN, not with its availability to donate electrons to the two neighbor centers, N1a and N3, whose reduction takes place on a slower timescale [51] or with its association with $\mathrm{NADH}$. According to this scenario, MD, EGCG, and $\mathrm{H}_{2} \mathrm{O}_{2}$, but not QC, may directly interact with FMN and alter its electronic configuration, thus reducing DL emission.

Nevertheless, these points need to be further addressed by detailed investigations with specific inhibitors of Complex I. However, it is noteworthy that our previous studies using Jurkat cells [15] and a different cell system [38], the budding yeast Saccharomyces cerevisiae, have indicated that $\mathrm{DL}$ is correlated with the activity of the Complex I of the mitochondrial respiratory chain but not with the existence of DNA or microtubule damage. Remarkably, these two different cell types, as well as the human glioblastoma U87 cell line produced a closely similar DL emission profile under control conditions (not shown). Taken together, these findings suggest that DL may not be cell-type specific and encourage further studies toward the use of DL spectroscopy in investigating mitochondrial dysfunctions in various diseases or in cancer diagnosis. Having in view the growing interest of using DL spectroscopy in clinical applications [3135], our results lend further support for the development of this methodology as a valuable tool of investigation and diagnosis.

\section{Acknowledgments}

This work is partially supported by the Sectorial Operational Programme Human Resources Development (SOP HRD), financed from the European Social Fund and by the Romanian Government under the Contract no. POSDRU/89/1.5/S/64109 and by a Grant of the Romanian National Authority for Scientific Research, CNCSUEFISCDI, Project no. PN-II-ID-PCE-2011-3-0800, no. $342 / 2011$.

\section{References}

[1] M. K. Johnson and G. Loo, "Effects of epigallocatechin gallate and quercetin on oxidative damage to cellular DNA," Mutation Research-DNA Repair, vol. 459, no. 3, pp. 211-218, 2000. 
[2] D. W. Han, M. H. Lee, H. H. Kim, S. H. Hyon, and J. C. Park, "Epigallocatechin-3-gallate regulates cell growth, cell cycle and phosphorylated nuclear factor- $\kappa \mathrm{B}$ in human dermal fibroblasts," Acta Pharmacologica Sinica, vol. 32, no. 5, pp. 637-646, 2011.

[3] C. Stresemann, B. Brueckner, T. Musch, H. Stopper, and F. Lyko, "Functional diversity of DNA methyltransferase inhibitors in human cancer cell lines," Cancer Research, vol. 66, no. 5, pp. 2794-2800, 2006.

[4] H. Wu, B. Zhu, Y. Shimoishi, Y. Murata, and Y. Nakamura, "(-)-Epigallocatechin-3-gallate induces up-regulation of Th1 and Th2 cytokine genes in Jurkat T cells," Archives of Biochemistry and Biophysics, vol. 483, no. 1, pp. 99-105, 2009.

[5] H. Nakagawa, K. Hasumi, J. T. Woo, K. Nagai, and M. Wachi, "Generation of hydrogen peroxide primarily contributes to the induction of $\mathrm{Fe}(\mathrm{II})$-dependent apoptosis in Jurkat cells by (-) -epigallocatechin gallate," Carcinogenesis, vol. 25, no. 9, pp. 1567-1574, 2004.

[6] S. Matzno, Y. Yamaguchi, T. Akiyoshi, T. Nakabayashi, and K. Matsuyama, "An attempt to evaluate the effect of vitamin K3 using as an enhancer of anticancer agents," Biological and Pharmaceutical Bulletin, vol. 31, no. 6, pp. 1270-1273, 2008.

[7] D. Chen, K. G. Daniel, M. S. Chen, D. J. Kuhn, K. R. LandisPiwowar, and Q. P. Dou, "Dietary flavonoids as proteasome inhibitors and apoptosis inducers in human leukemia cells," Biochemical Pharmacology, vol. 69, no. 10, pp. 1421-1432, 2005.

[8] J. H. Jeong, J. Y. An, Y. T. Kwon, J. G. Rhee, and Y. J. Lee, "Effects of low dose quercetin: cancer cell-specific inhibition of cell cycle progression," Journal of Cellular Biochemistry, vol. 106, no. 1, pp. 73-82, 2009.

[9] G. C. Yen, P. D. Duh, H. L. Tsai, and S. L. Huang, "Pro-oxidative properties of flavonoids in human lymphocytes," Bioscience, Biotechnology and Biochemistry, vol. 67, no. 6, pp. 1215-1222, 2003.

[10] M. Fiorani, A. Guidarelli, M. Blasa et al., "Mitochondria accumulate large amounts of quercetin: prevention of mitochondrial damage and release upon oxidation of the extramitochondrial fraction of the flavonoid," Journal of Nutritional Biochemistry, vol. 21, no. 5, pp. 397-404, 2010.

[11] U. de Marchi, L. Biasutto, S. Garbisa, A. Toninello, and M. Zoratti, "Quercetin can act either as an inhibitor or an inducer of the mitochondrial permeability transition pore: a demonstration of the ambivalent redox character of polyphenols," Biochimica et Biophysica Acta, vol. 1787, no. 12, pp. 1425-1432, 2009.

[12] D. J. Dorta, A. A. Pigoso, F. E. Mingatto et al., "The interaction of flavonoids with mitochondria: effects on energetic processes," Chemico-Biological Interactions, vol. 152, no. 2-3, pp. 67-78, 2005.

[13] D. Metodiewa, A. K. Jaiswal, N. Cenas, E. Dickancaité, and J. Segura-Aguilar, "Quercetin may act as a cytotoxic prooxidant after its metabolic activation to semiquinone and quinoidal product," Free Radical Biology and Medicine, vol. 26, no. 1-2, pp. 107-116, 1999.

[14] R. Ferraresi, L. Troiano, E. Roat et al., "Essential requirement of reduced glutathione (GSH) for the anti-oxidant effect of the flavonoid quercetin," Free Radical Research, vol. 39, no. 11, pp. 1249-1258, 2005.

[15] I. Baran, C. Ganea, A. Scordino et al., "Effects of menadione, hydrogen peroxide, and quercetin on apoptosis and delayed luminescence of human leukemia jurkat T-cells," Cell Biochemistry and Biophysics, vol. 58, no. 3, pp. 169-179, 2010.

[16] G. N. Kim and H. D. Jang, "Protective mechanism of quercetin and rutin using glutathione metabolism on $\mathrm{H}_{2} \mathrm{O}_{2}$-induced oxidative stress in HepG2 cells," Annals of the New York Academy of Sciences, vol. 1171, pp. 530-537, 2009.

[17] B. M. Kim, Y. J. Choi, Y. Han, Y. S. Yun, and S. H. Hong, "N,N-dimethyl phytosphingosine induces caspase-8-dependent cytochrome $c$ release and apoptosis through ROS generation in human leukemia cells," Toxicology and Applied Pharmacology, vol. 239, no. 1, pp. 87-97, 2009.

[18] S. Piyaviriyakul, K. Shimizu, T. Asakawa, T. Kan, P. Siripong, and N. Oku, "Anti-angiogenic activity and intracellular distribution of epigallocatechin-3-gallate analogs," Biological and Pharmaceutical Bulletin, vol. 34, no. 3, pp. 396-400, 2011.

[19] I. Laux and A. Nel, "Evidence that oxidative stress-induced apoptosis by menadione involves Fas-dependent and Fasindependent pathways," Clinical Immunology, vol. 101, no. 3, pp. 335-344, 2001.

[20] J. J. Brière, D. Schlemmer, D. Chretien, and P. Rustin, "Quinone analogues regulate mitochondrial substrate competitive oxidation," Biochemical and Biophysical Research Communications, vol. 316, no. 4, pp. 1138-1142, 2004.

[21] M. Floreani and F. Carpenedo, "One- and two-electron reduction of menadione in guinea-pig and rat cardiac tissue," General Pharmacology, vol. 23, no. 4, pp. 757-762, 1992.

[22] A. Rasola and M. Geuna, "A flow cytometry assay simultaneously detects independent apoptotic parameters," Cytometry, vol. 45, pp. 151-157, 2001.

[23] W. Yin, X. Li, S. Feng et al., "Plasma membrane depolarization and $\mathrm{Na}, \mathrm{K}$-ATPase impairment induced by mitochondrial toxins augment leukemia cell apoptosis via a novel mitochondrial amplification mechanism," Biochemical Pharmacology, vol. 78, no. 2, pp. 191-202, 2009.

[24] S. Y. Chien, Y. C. Wu, J. G. Chung et al., "Quercetin-induced apoptosis acts through mitochondrial- and caspase-3-dependent pathways in human breast cancer MDA-MB-231 cells," Human and Experimental Toxicology, vol. 28, no. 8, pp. 493503, 2009.

[25] D. E. Godar, "UVA1 radiation triggers two different final apoptotic pathways," Journal of Investigative Dermatology, vol. 112, no. 1, pp. 3-12, 1999.

[26] J. H. Wang, J. Cheng, C. R. Li, M. Ye, Z. Ma, and F. Cai, "Modulation of $\mathrm{Ca}^{2+}$ signals by epigallocatechin-3-gallate(EGCG) in cultured rat hippocampal neurons," International Journal of Molecular Sciences, vol. 12, no. 1, pp. 742-754, 2011.

[27] I. Baran, C. Ganea, A. Scordino et al., "Apoptosis, cell cycle and delayed luminescence of human leukemia Jurkat T-cells under proton-irradiation and oxidative stress conditions," in Activity Report Istituto Nazionale Di Fisica Nucleare Laboratori Nazionali Del Sud, pp. 246-249, Arti Grafiche Le Ciminiere Catania, Catania, Italia, 2010.

[28] I. Verbrugge, E. H. J. Wissink, R. W. Rooswinkel et al., "Combining radiotherapy with APO010 in cancer treatment," Clinical Cancer Research, vol. 15, no. 6, pp. 2031-2038, 2009.

[29] S. F. Zerp, R. Stoter, G. Kuipers et al., "AT-101, a small molecule inhibitor of anti-apoptotic Bcl-2 family members, activates the SAPK/JNK pathway and enhances radiation-induced apoptosis," Radiation Oncology, vol. 4, no. 1, article 47, 2009.

[30] B. Gong and A. Almasan, "Apo2 ligand/TNF-related apoptosis-inducing ligand and death receptor 5 mediate the apoptotic signaling induced by ionizing radiation in leukemic cells," Cancer Research, vol. 60, no. 20, pp. 5754-5760, 2000.

[31] M. A. E. J. Ortner, B. Ebert, E. Hein et al., "Time gated fluorescence spectroscopy in Barrett's oesophagus," Gut, vol. 52, no. 1, pp. 28-33, 2003. 
[32] F. Musumeci, L. A. Applegate, G. Privitera, A. Scordino, S. Tudisco, and H. J. Niggli, "Spectral analysis of laser-induced ultraweak delayed luminescence in cultured normal and tumor human cells: temperature dependence," Journal of Photochemistry and Photobiology B, vol. 79, no. 2, pp. 93-99, 2005.

[33] H. W. Kim, S. B. Sim, C. K. Kim et al., "Spontaneous photon emission and delayed luminescence of two types of human lung cancer tissues: adenocarcinoma and Squamous cell carcinoma," Cancer Letters, vol. 229, no. 2, pp. 283-289, 2005.

[34] W. Kemmner, K. Wan, S. Rüttinger et al., "Silencing of human ferrochelatase causes abundant protoporphyrin-IX accumulation in colon cancer," The FASEB Journal, vol. 22, no. 2, pp. 500-509, 2008.

[35] E. G. Mik, T. Johannes, C. J. Zuurbier et al., "In vivo mitochondrial oxygen tension measured by a delayed fluorescence lifetime technique," Biophysical Journal, vol. 95, no. 8, pp. 3977-3990, 2008.

[36] V. Goltsev, P. Chernev, I. Zaharieva, P. Lambrev, and R. J. Strasser, "Kinetics of delayed chlorophyll a fluorescence registered in milliseconds time range," Photosynthesis Research, vol. 84, no. 1-3, pp. 209-215, 2005.

[37] Y. Guo and J. Tan, "A kinetic model structure for delayed fluorescence from plants,” BioSystems, vol. 95, no. 2, pp. 98-103, 2009.

[38] I. Baran, C. Ganea, I. Ursu et al., "Effects of nocodazole and ionizing radiation on cell proliferation and delayed luminescence," Romanian Journal of Physics, vol. 54, no. 5-6, pp. 557$567,2009$.

[39] S. Tudisco, A. Scordino, G. Privitera, I. Baran, and F. Musumeci, "ARETUSA - advanced research equipment for fast ultraweak luminescence analysis: new developments," $\mathrm{Nu}$ clear Instruments and Methods in Physics Research A, vol. 518, no. 1-2, pp. 463-464, 2004.

[40] J. Slawinski, "Luminescence research and its relation to ultraweak cell radiation," Experientia, vol. 44, no. 7, pp. 559-571, 1988.

[41] P. Felker, S. Izawa, N. E. Good, and A. Haug, "Effects of electron transport inhibitors on millisecond delayed light emission from chloroplasts," Biochimica et Biophysica Acta, vol. 325, no. 1, pp. 193-196, 1973.

[42] E. Hideg, M. Kobayashi, and H. Inaba, "Spontaneous ultraweak light emission from respiring spinach leaf mitochondria," Biochimica et Biophysica Acta, vol. 1098, no. 1, pp. 27-31, 1991.

[43] M. Katsumata, A. Takeuchi, K. Kazumura, and T. Koike, "New feature of delayed luminescence: preillumination-induced concavity and convexity in delayed luminescence decay curve in the green alga Pseudokirchneriella subcapitata," Journal of Photochemistry and Photobiology B, vol. 90, no. 3, pp. 152-162, 2008.

[44] I. Baran, C. Ganea, I. Ursu et al., "Fluorescence properties of quercetin in human leukemia Jurkat T-Cells," Romanian Journal of Physics, vol. 56, no. 3-4, pp. 388-398, 2011.

[45] D. Erba, P. Riso, A. Colombo, and G. Testolin, "Supplementation of Jurkat T cells with green tea extract decreases oxidative damage due to iron treatment," Journal of Nutrition, vol. 129, no. 12 , pp. 2130-2134, 1999.

[46] L. C. Wilms, J. C. S. Kleinjans, E. J. C. Moonen, and J. J. Briedé, "Discriminative protection against hydroxyl and superoxide anion radicals by quercetin in human leucocytes in vitro," Toxicology In Vitro, vol. 22, no. 2, pp. 301-307, 2008.
[47] C. Carrasco-Pozo, M. L. Mizgier, H. Speisky, and M. Gotteland, "Differential protective effects of quercetin, resveratrol, rutin and epigallocatechin gallate against mitochondrial dysfunction induced by indomethacin in Caco-2 cells," ChemicoBiological Interactions, vol. 195, pp. 199-205, 2012.

[48] T. Samuel, K. Fadlalla, L. Mosley, V. Katkoori, T. Turner, and U. Manne, "Dual-mode interaction between quercetin and DNAdamaging drugs in cancer cells," Anticancer Research, vol. 32, pp. 61-71, 2012.

[49] K. A. Foster, F. Galeffi, F. J. Gerich, D. A. Turner, and M. Müller, "Optical and pharmacological tools to investigate the role of mitochondria during oxidative stress and neurodegeneration," Progress in Neurobiology, vol. 79, no. 3, pp. 136-171, 2006.

[50] T. E. Swartz, S. B. Corchnoy, J. M. Christie et al., "The photocycle of a flavin-binding domain of the blue light photoreceptor phototropin," Journal of Biological Chemistry, vol. 276, no. 39, pp. 36493-36500, 2001.

[51] M. L. Verkhovskaya, N. Belevich, L. Euro, M. Wikström, and M. I. Verkhovsky, "Real-time electron transfer in respiratory complex I," Proceedings of the National Academy of Sciences of the United States of America, vol. 105, no. 10, pp. 3763-3767, 2008.

[52] X. Xu and E. A. Arriaga, "Qualitative determination of superoxide release at both sides of the mitochondrial inner membrane by capillary electrophoretic analysis of the oxidation products of triphenylphosphonium hydroethidine," Free Radical Biology and Medicine, vol. 46, no. 7, pp. 905-913, 2009. 


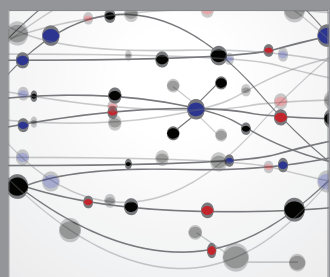

The Scientific World Journal
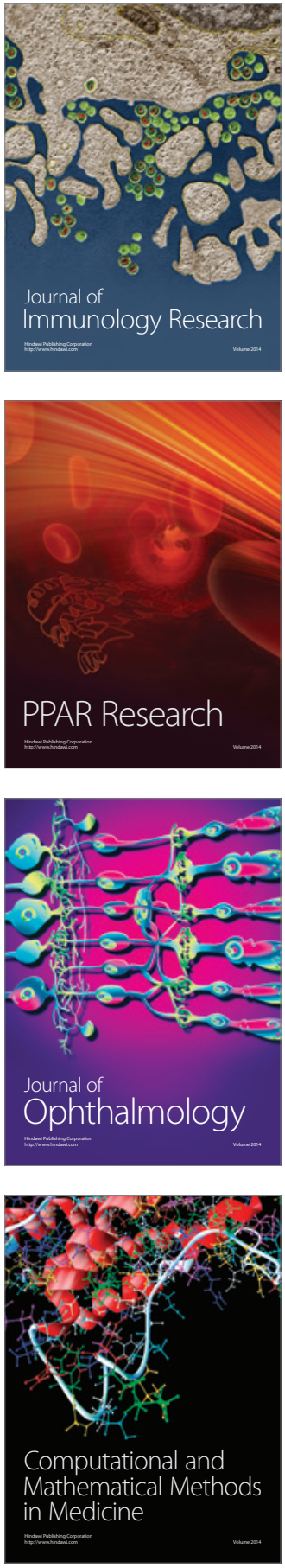

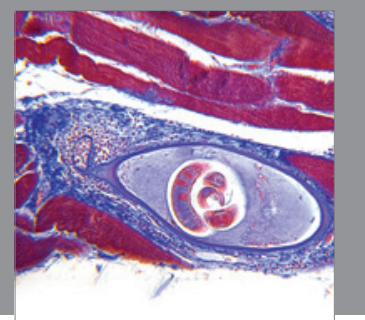

Gastroenterology

Research and Practice
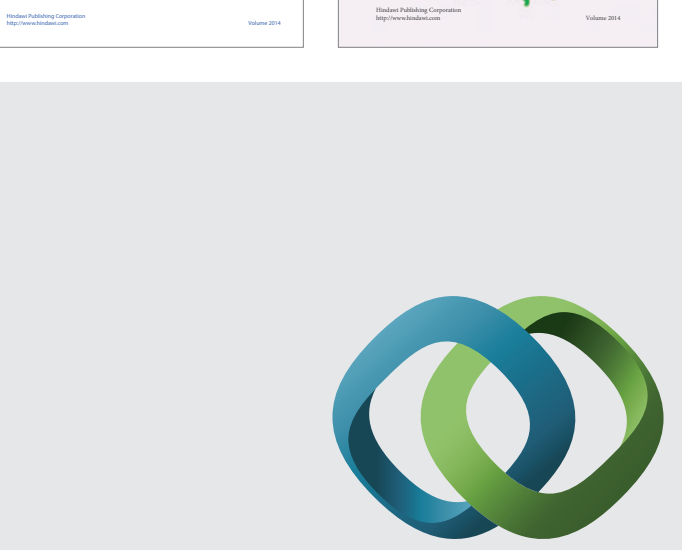

\section{Hindawi}

Submit your manuscripts at

http://www.hindawi.com
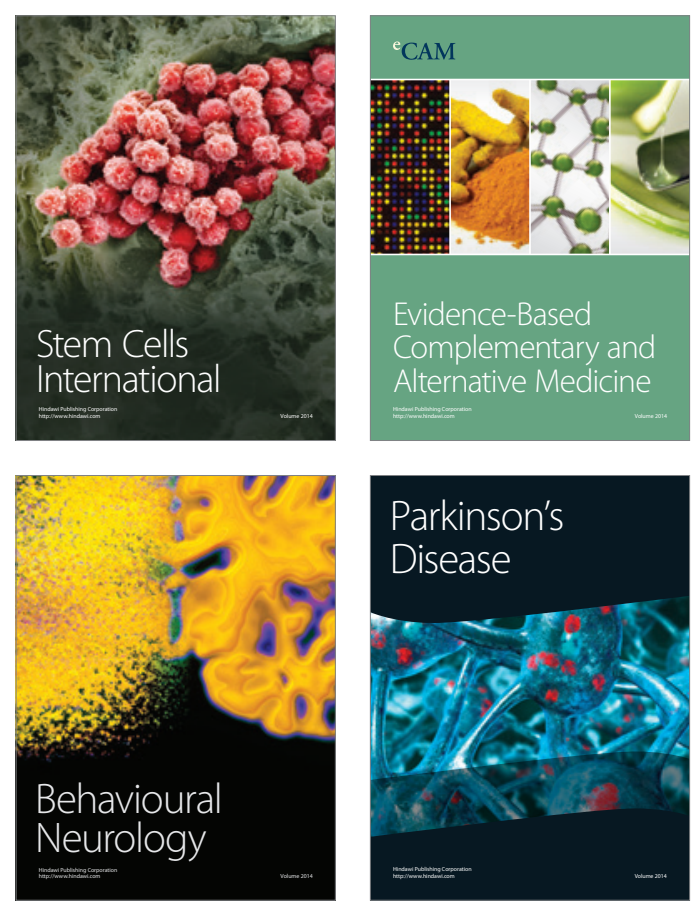

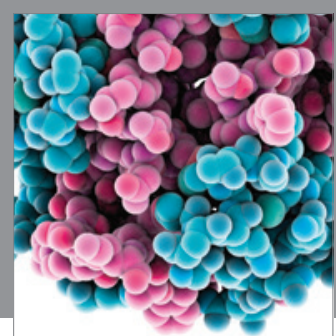

Journal of
Diabetes Research

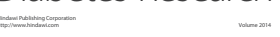

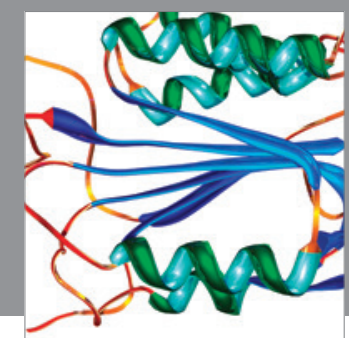

Disease Markers
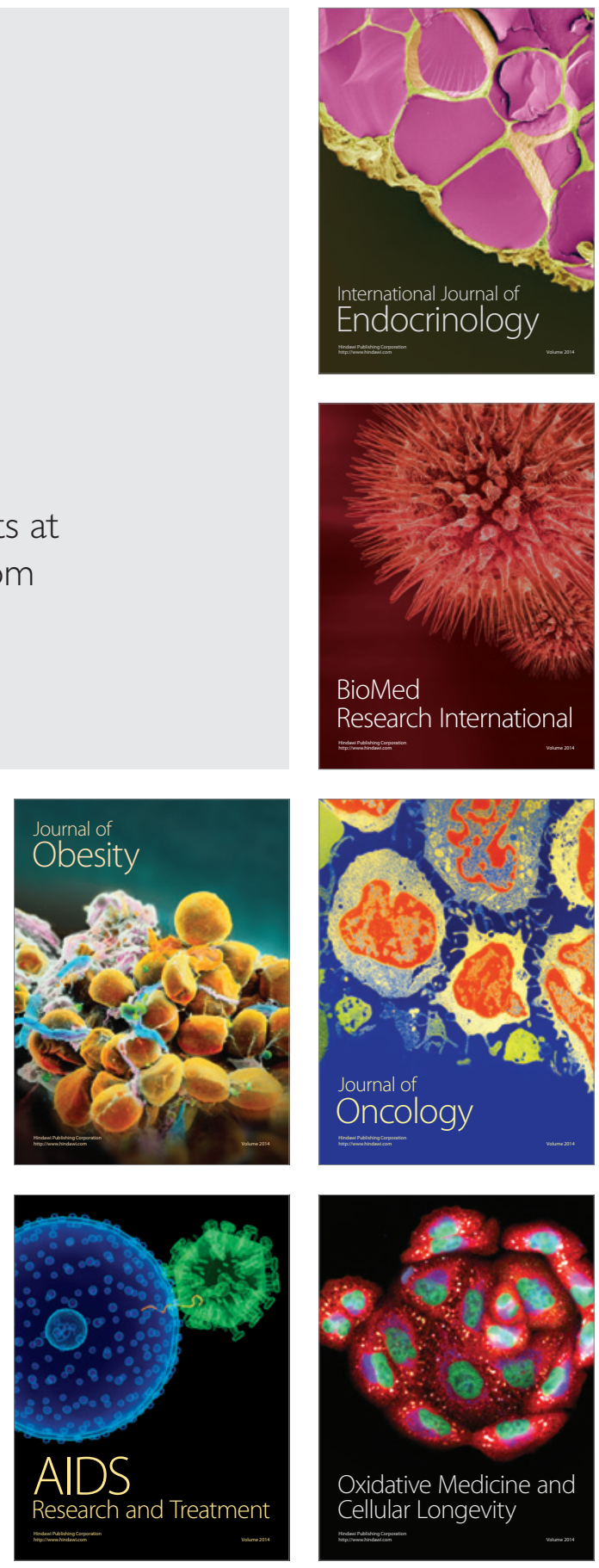